\title{
Optimization of Sectional Dimensions of I-Section Flange Beams and Recommendations for IS 808: 1989
}

\author{
Himanshu Gaur ${ }^{1}$, Krishna Murari ${ }^{1}$, Biswajit Acharya ${ }^{2}$ \\ ${ }^{1}$ Civil Engineering Department, Jaypee University of Engineering \& Technology, Guna, India \\ ${ }^{2}$ Civil Engineering Department, College of Engineering, Rajasthan Technological University, Kota, India \\ Email: himanshugaur82@gmail.com
}

Received 18 January 2016; accepted 28 March 2016; published 31 March 2016

Copyright (C) 2016 by authors and Scientific Research Publishing Inc.

This work is licensed under the Creative Commons Attribution International License (CC BY). http://creativecommons.org/licenses/by/4.0/

(c) (i) Open Access

\begin{abstract}
This study covers optimization of I-sectional flange beams. Scope of this study is limited to medium weight flange beams of Table 1 of IS 808:1983 but it can be further extended for the other sections of this code. Best possible geometric shape of the cross-section is found for maximum performance of the beam with minimum material consumption. All possible loading conditions are considered in the study for which a beam in flexure undergoes in its life. ANSYS software program is used for the analysis and optimizing the sections. It is found that sections MB 125, MB 300 and MB 400 of Table 1 of IS 808 are not the optimum sections but other alternative of these crosssections is available which within the same material consumption performs better than these sections of IS code.
\end{abstract}

\section{Keywords}

Finite Element Analysis, Flange Beam, I-Section, Optimization

\section{Introduction}

Indian standard code of practice IS 808: 1989 was last incorporated for its amendments in 2002. This standard covers the nominal dimensions, mass and sectional properties of hot rolled sloping flange beam and column sections, sloping and parallel flange channel sections and equal and unequal leg angle sections. These sections are used by the designers and manufactures countrywide. Scope of this study covers studying the performance of medium weight I-section flange beams specified in Table 1 of IS 808: 1989 [1]. Performance of the other sections of this code can be judged with the same methodology and even mega sections can be recommended for 
Table 1. Nominal dimensions, mass and sectional properties of Indian standard medium flange beams.

\begin{tabular}{|c|c|c|c|c|c|c|c|c|c|c|c|c|c|c|c|}
\hline \multirow{3}{*}{ Designation } & \multirow{3}{*}{$\begin{array}{c}\text { Mass, } \\
\text { M } \\
\mathrm{Kg} / \mathrm{m}\end{array}$} & \multirow{3}{*}{$\begin{array}{c}\text { Sectional } \\
\text { Area, A } \\
\mathrm{cm}^{2}\end{array}$} & \multicolumn{7}{|c|}{ Dimensions } & \multicolumn{6}{|c|}{ Sectional Properties } \\
\hline & & & $\mathrm{D}$ & B & $\mathrm{t}$ & $\mathrm{T}$ & $\begin{array}{l}\text { Flange Slope, } \\
\operatorname{Max} \alpha\end{array}$ & $\mathrm{R}_{1}$ & $\mathrm{R}_{2}$ & $\mathrm{I}_{\mathrm{x}}$ & $\mathrm{I}_{\mathrm{y}}$ & $r_{x}$ & $\mathrm{r}_{\mathrm{y}}$ & $\mathrm{Z}_{\mathrm{x}}$ & $\mathrm{Z}_{\mathrm{y}}$ \\
\hline & & & $\mathrm{mm}$ & $\mathrm{mm}$ & $\mathrm{mm}$ & $\mathrm{mm}$ & deg & $\mathrm{mm}$ & $\mathrm{mm}$ & $\mathrm{cm}^{4}$ & $\mathrm{~cm}^{4}$ & $\mathrm{~cm}$ & $\mathrm{~cm}$ & $\mathrm{~cm}^{3}$ & $\mathrm{~cm}^{3}$ \\
\hline (1) & $(2)$ & (3) & (4) & (5) & (6) & (7) & (8) & (9) & (10) & (11) & (12) & (13) & (14) & (15) & $(16)$ \\
\hline MB 100 & 8.9 & 11.4 & 100 & 50 & 4.7 & $7 / 0$ & 98.0 & 9.0 & 4.5 & 183 & 12.9 & 4.00 & 1.05 & 36.6 & 5.16 \\
\hline MB 125 & 13.3 & 17.0 & 125 & 70 & 5.0 & 8.0 & 98.0 & 9.0 & 4.5 & 445 & 38.5 & 5.16 & 1.51 & 71.2 & 11.2 \\
\hline MB 150 & 15.0 & 19.1 & 150 & 75 & 5.0 & 8.0 & 98.0 & 9.0 & 4.5 & 718 & 46.8 & 6.13 & 1.57 & 95.7 & 12.5 \\
\hline MB 175 & 19.6 & 25.0 & 175 & 85 & 5.8 & 9.0 & 98.0 & 10.0 & 5.0 & 1260 & 76.7 & 7.13 & 1.75 & 144 & 18.0 \\
\hline MB 200 & 24.2 & 30.8 & 200 & 100 & 5.7 & 10.0 & 98.0 & 11.0 & 5.5 & 2120 & 137 & 8.29 & 2.11 & 212 & 27.4 \\
\hline MB 225 & 31.1 & 39.7 & 225 & 110 & 6.5 & 11.8 & 98.0 & 12.0 & 6.0 & 3440 & 218 & 9.31 & 2.34 & 306 & 39.7 \\
\hline MB 250 & 37.3 & 47.5 & 250 & 125 & 6.9 & 12.5 & 98.0 & 13.0 & 6.5 & 5130 & 335 & 10.4 & 2.65 & 410 & 53.5 \\
\hline MB 300 & 46.0 & 58.6 & 300 & 140 & 7.7 & 13.1 & 98.0 & 14.0 & 7.0 & 8990 & 486 & 12.4 & 2.86 & 599 & 69.5 \\
\hline MB 350 & 52.4 & 66.7 & 350 & 140 & 8.1 & 14.2 & 98.0 & 14.0 & 7.0 & 13,600 & 538 & 14.3 & 2.84 & 779 & 76.8 \\
\hline MB 400 & 61.5 & 78.4 & 400 & 140 & 8.9 & 16.0 & 98.0 & 14.0 & 7.0 & 20,500 & 622 & 16.2 & 2.82 & 1020 & 88.9 \\
\hline MB 450 & 72.4 & 92.2 & 450 & 150 & 9.4 & 17.4 & 98.0 & 15.0 & 7.5 & 30,400 & 834 & 18.2 & 3.01 & 1350 & 111 \\
\hline MB 500 & 86.9 & 111 & 500 & 180 & 10.2 & 17.2 & 98.0 & 17.0 & 8.5 & 45,200 & 1370 & 20.2 & 3.52 & 1810 & 152 \\
\hline MB 550 & 104 & 132 & 550 & 190 & 11.2 & 19.3 & 98.0 & 18.0 & 9.0 & 64,900 & 1830 & 22.2 & 3.73 & 2360 & 193 \\
\hline MB 600 & 123 & 156 & 600 & 210 & 12.0 & 20.3 & 98.0 & 20.0 & 10.0 & 91,800 & 2650 & 24.2 & 4.12 & 3060 & 252 \\
\hline
\end{tabular}

this code.

Since 2002, there have been tremendous improvements in the computation capabilities of software programs with high performance hardware system. Looking close to the sections of Table 1 of IS 808: 1989, it seems unreasonable when flange slope does not change when the depth of the sections is changing from $50 \mathrm{~mm}$ to 210 $\mathrm{mm}$. Even few of the sections like MB 300, MB 350 and MB 400 are have same width of the section when the depth of them varies from $300 \mathrm{~mm}$ to $400 \mathrm{~mm}$.

Engineers have always tried to optimize the structural design for material saving perspective and cost reduction. Optimization can be done with respect to size, shape and topology of the structure. The most effective and efficient tool for optimization is topological optimization if loading and boundary conditions are fixed [2]. Size optimization is dealt with analysis which is called designing in engineering term.

In 2009, K. Ghabraie [3] et al. utilized optimization by Evolutionary Structural Optimization (ESO) method for optimizing the shape of underground excavations. In 2014, Lauren L. Beghini [4] et al. emphasized the benefits of using topological optimization which on one hand satisfied the need of engineers and on other hand satisfied the architectural demand.

In this paper, shape optimization is performed on I-sections flange beams. Performance of the beam is studied by changing any particular sectional dimension (Figure 1) within permissible geometric limits. Studying these variations helps in deciding optimum value of the input dimension.

For a particular beam section, there should definitely be a unique combination of sectional parameters (Figure 1) i.e. depth of the section (D), width of the section (B), radius of fillet $\left(\mathrm{R}_{1}\right)$, thickness of web (t), flange thickness $(T)$ and flange slope $(\alpha)$ for which section gives maximum performance for applied loadings with minimum material consumption. It may also possible that for more than one combination of these parameters, section performs optimum.

For studying these realistically, let us discuss first the variation of stresses within the section as the beam is subjected to bending. For designing optimum section in flexure, beam should also be considered for torsion in case of any eccentric loading.

\section{Variation of Stresses along the Cross-Section of the Beam}

Figure 2 shows a beam of rectangular cross-section with concentrated loading. Variation of bending and shear- 


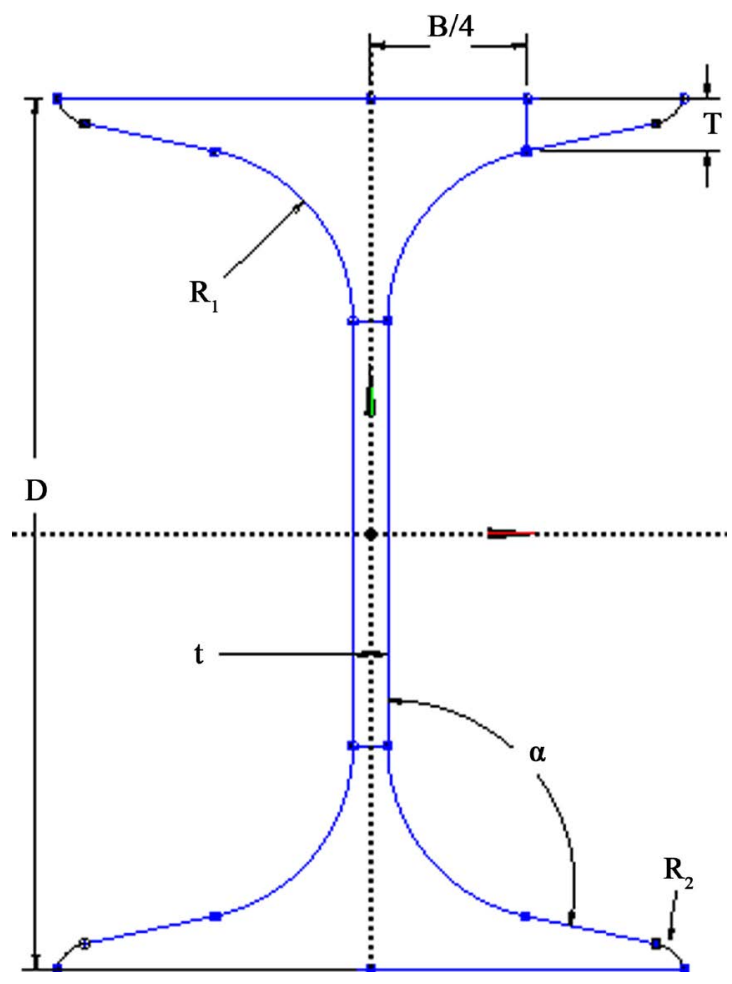

Figure 1. Nomination of sectional dimensions is shown in the figure.
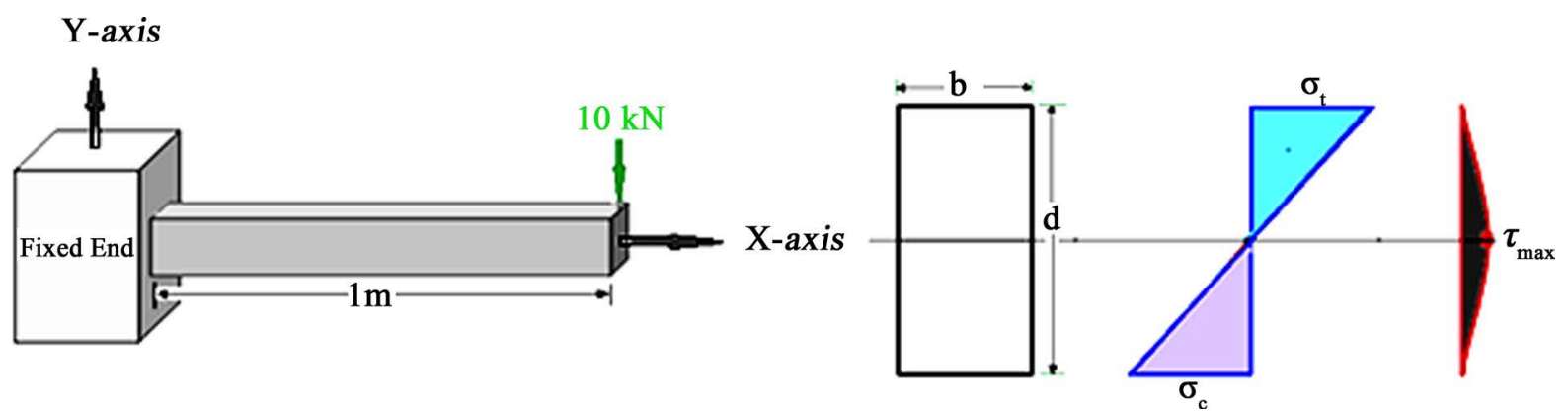

Figure 2. Beam with loading. (Distribution of stresses along the cross-section).

ing stresses across the cross-section is also shown in this figure. With the strength of material practice, it is found that magnitude of the maximum bending stress either at top or bottom layer of the cross-section is 8 to 11 times higher than that of shearing stress induces at the neutral axis [5] [6]. Numerically this variation depends upon the geometric shape of the cross-section.

Talking about the torsional stresses, these are zero at the centre of the cross-section then varies linearly and finally becoming maximum at the outer layer. Variation of bending stress along the cross-section is linear whereas that of shearing stresses is in a curved parabolic path as shown in Figure 2.

\section{Problem Statement}

Studying the numerical values of stresses along the cross section, most robust section can be decided on the basis of that best fits in compensating these stresses. Figure 3 shows two of the alternatives of a cross section. First one is MB 350 of IS 808 and the second one is the probable robust alternative of this section.

In the alternative section, radius of fillet $\left(R_{1}\right)$ is increased, depth is decreased and flange width is increased a bit. These all changes are made with an understanding of variation of stresses within the section. Finalizing any one of them as the best is not possible until unless performance of the beam is not known as each of these input 
parameter changes within a section.

ANSYS is the best tool for resolving this kind of optimization problems. Beam performance is studied by varying each of these input parameters and conclusions are made for the sections of Table 1 of IS: 808 for their shape.

\section{Methodology Used for Optimisation}

Geometry shown in Figure 1 is created such that section changes symmetrically for varying any input parameter. It is imperative to keep at least one input geometric parameter constant as varying all the input geometric parameter may lead to generation of totally new optimum section which matches nowhere with the sections of IS: 808. So, depth of the section is selected as constant which also matches with the variation of sections given in Table 1 of IS: 808. Other input sectional parameters are varied within the geometric limits of the section. For convenience beam is taken 1 meter long and kept fixed at one end (Figure 4). Radius $\mathbf{R}_{\mathbf{2}}$ (Figure 1) could not be taken as the input parameter as it tremendously reduces the range of other input parameters. So after analysis, whatever the value program adopt for it, is selected finally.

Strategies are used for selecting best output parameter that optimizes the section while consuming minimum analysis time. Different simulations are tried using output parameters such as area of cross-section, different stress, different strains, material volume and strain energy etc. Three output parameters mass of the beam, safety factor and total deformation are found to be capable enough for optimizing these sections. Numerically, program
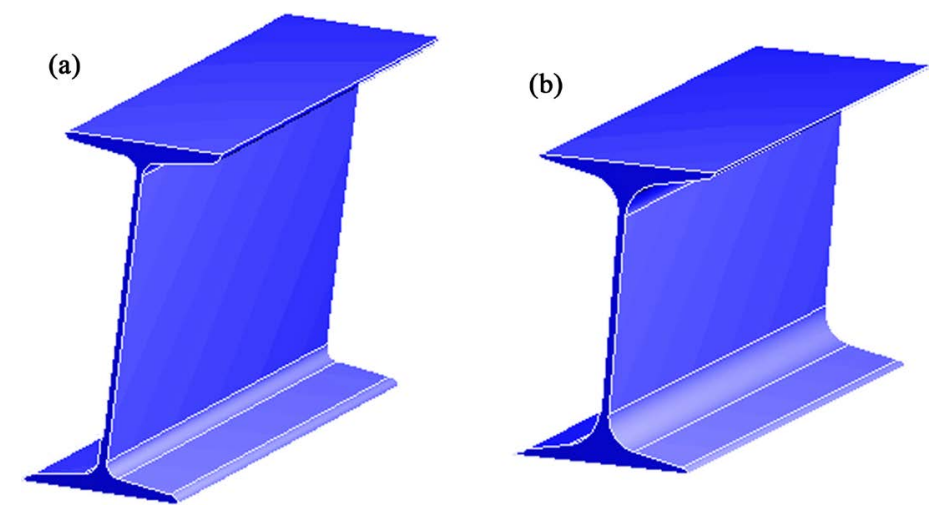

Figure 3. Two alternate sections with different geometric shapes. (a) IS section, (b) proposed optimum section.

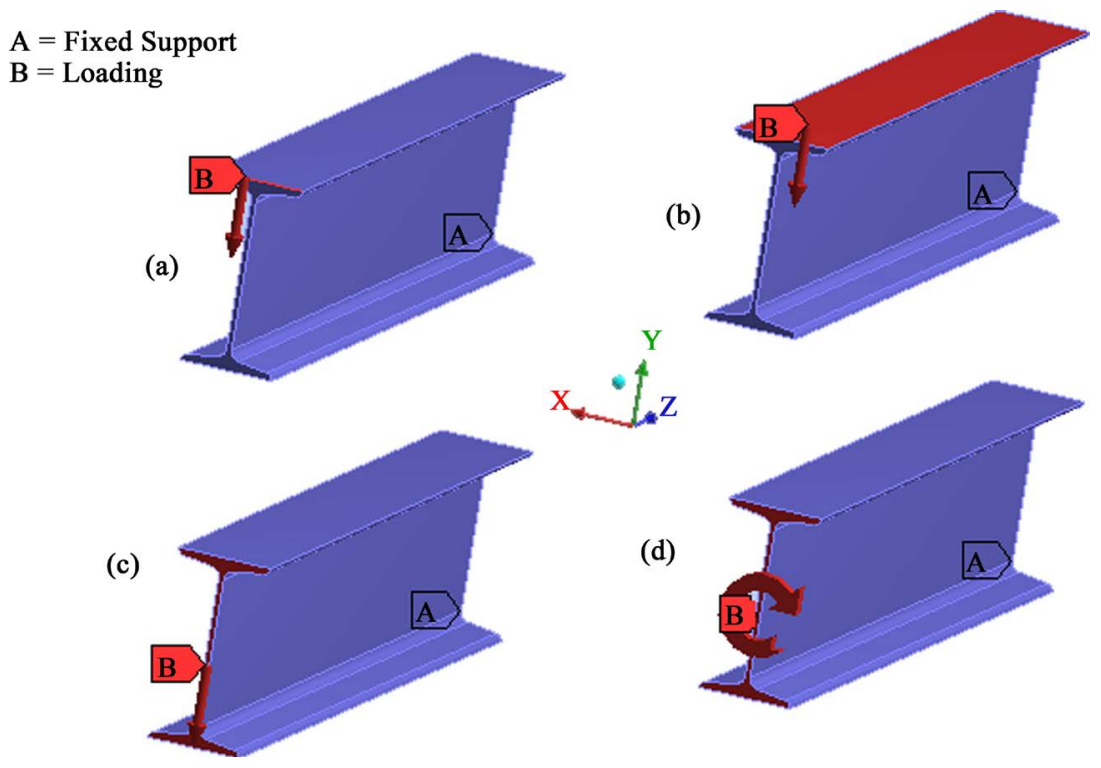

Figure 4. Different loading conditions (a) Line load, (b) pressure load, (c) surface load and (d) moment at the free end. 
calculates safety factor from stresses induced in the structure. So, theoretically, stresses and strains (deformation) are enough to measure the performance of the beam. Mass of the beam is also opted as output parameter as it has to be minimized. Each model is subjected to all possible loading conditions which it can undergo in its lifetime and are depicted in Figure 4.

\section{Modelling \& Meshing}

With several trials of meshing, element shape and size is selected which converges with the theoretical results. Shape and size of the element is adopted such that within minimum analysis time it best converges to theoretical results.

Geometry of the structure in the present study possesses curved boundaries. Hence tetrahedral shape of the elements is adopted for the analysis to avoid generation of distorted and badly shaped elements by warping or skewing [7]-[10]. A good support for this is also found in the meshing statics. Figure 5 shows the statistics of meshing of section MB 125 of IS: 808 using tetrahedral elements with minimum size limit $0.015 \mathrm{~m}$.

Statistics shown in this figure are found to be in the approximate match for the other sections as well using these types of elements.

In this figure, aspect ratio of elements does not increase beyond 8.86 and the average value is 2.163. For the same element size and same geometric section if hexahedral elements were used than aspect ratio goes till 1136 with an average of 7.69. So with these statistics, using tetrahedral elements for analysis is preferable.

Another reason for adopting tetrahedral elements is observed in the convergence results of Figure 6 . In this

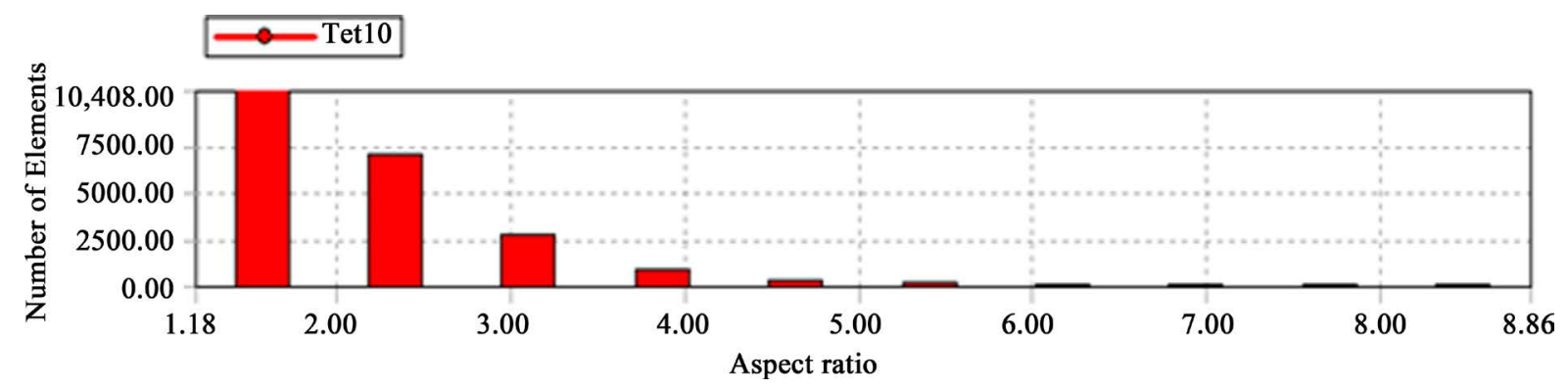

Figure 5. Figure shows the statistics of meshing using tetrahedral elements.

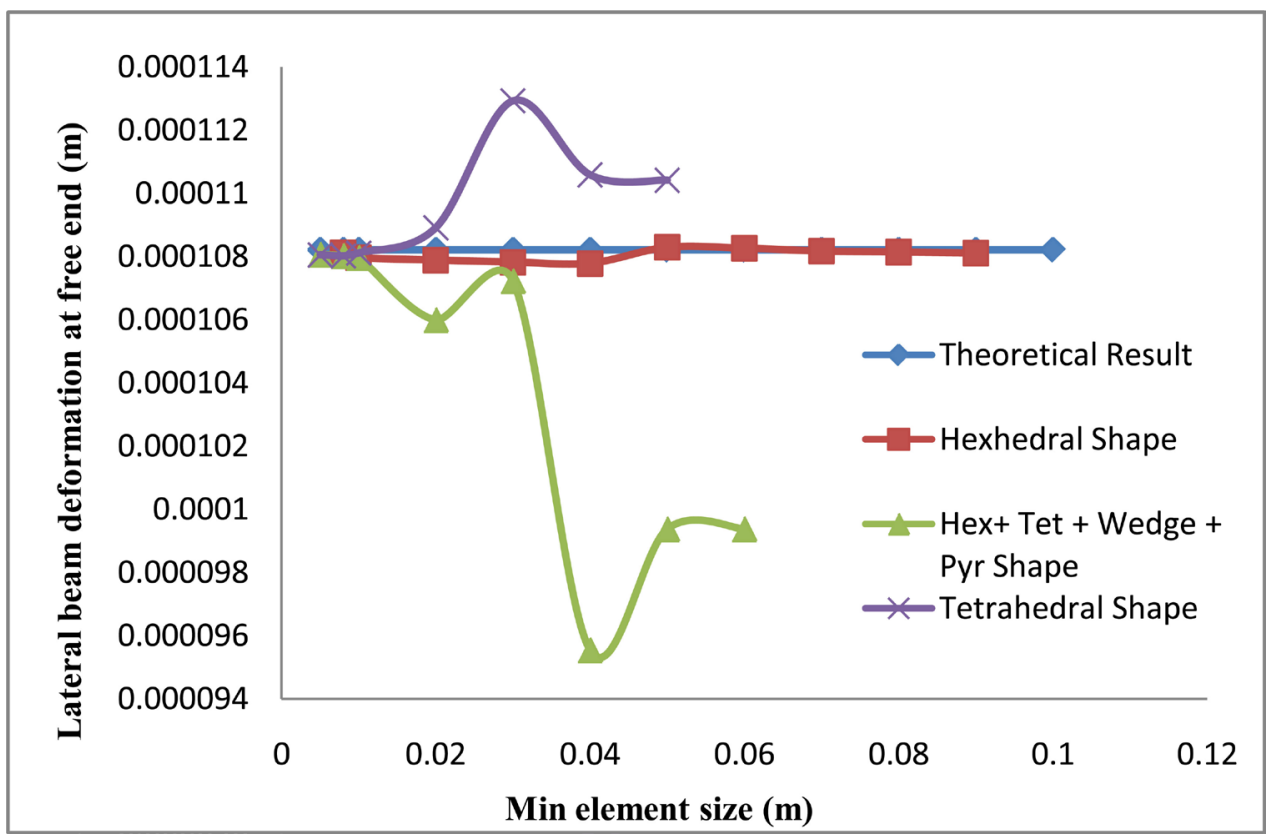

Figure 6. Figure shows the convergence results obtained for MB 125 section. 
figure, a smooth convergence of tetrahedral elements after $0.02 \mathrm{~m}$ element size is found which is not same in case of hexahedral elements. Smooth convergence again supports its use in the analysis.

Three dimensional, 10-node solid tetrahedral shape element that exhibits quadratic displacement behaviour is used for the analysis (Figure 7). This element possesses three degrees of freedom at each node in each spatial direction.

Although, using hexahedral elements when used with small elements size gives reasonable results but it in turn increases the running time of analysis because of increased degrees of freedom.

Furthermore, results of error estimation [11] in meshing are also found to be satisfactory (Figure 27).

\section{Validation of Results}

Total deflection of the beam is calculated considering both effects bending as well as shear. As for all sections, beam length is chosen to be $1 \mathrm{~m}$. So it is also possible that for increasing sectional dimensions, in case of deep sections shear deformations become high. So, for validation of results, following Timoshenko beam equation [5] [6] and [12] is used for calculating the total deflection:

$$
\frac{\mathrm{d}^{2} y}{\mathrm{~d} x^{2}}=\left[\frac{M}{E I}+\frac{k q}{A G}\right]
$$

where $M$ and $q$ is moment and shear force at any cross-section, $E$ is modulus of elasticity of material, $G$ is shearing modules, $A$ and $I$ are the area and moment of inertia of the cross-section and $k$ is the shear constant which depends upon the shape of beam cross-section. For I-section shear constant is calculated as under [6].

$$
k=\frac{A}{I t}\left[\frac{B D^{2}}{8}-\frac{h_{1}^{2}}{8}(B-t)\right]
$$

In this equation, all other parameters are as shown in Figure 1 and Figure 8. Area $A$ and moment of inertia $I$ of the section are calculated geometrically with the dimensions of Figure 8.

Solving the equation for a cantilever beam loaded with uniformly distributed load, deflection at the free end comes out to be.

$$
y=\frac{q l^{4}}{8 E I}+\frac{k}{A G} \frac{w l^{3}}{3}
$$

where $w$ is the magnitude of uniformly distributed load and $l$ is the length of the beam. Putting all the numerical values of these parameters, total deflection of beam at free end was calculated for validation of result.

\section{Variations in Parameters}

This section describes the behavior of the beam as the sectional dimensions vary in a section. Each parameter i.e. depth, radius of fillet, thickness of web, flange thickness, flange slope and width of the section, is varied by keeping all other parameters constant to understand the behavior of section thoroughly.
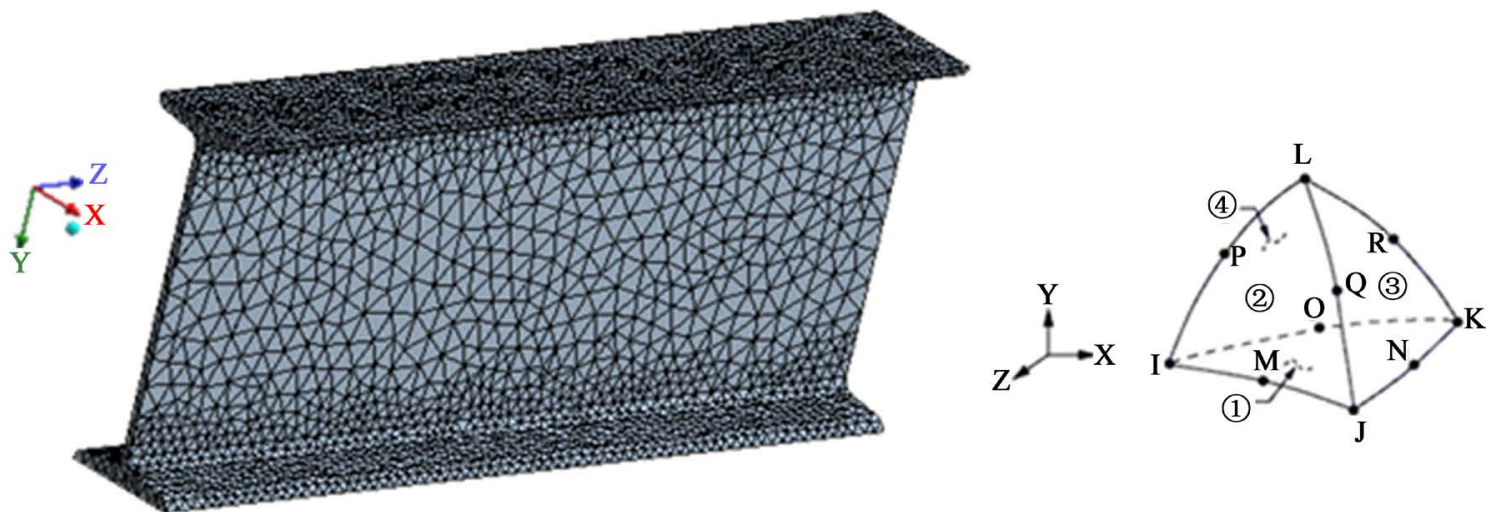

Figure 7. Meshing of the model with element shape (0.015 m minimum size, 21,129 elements). 


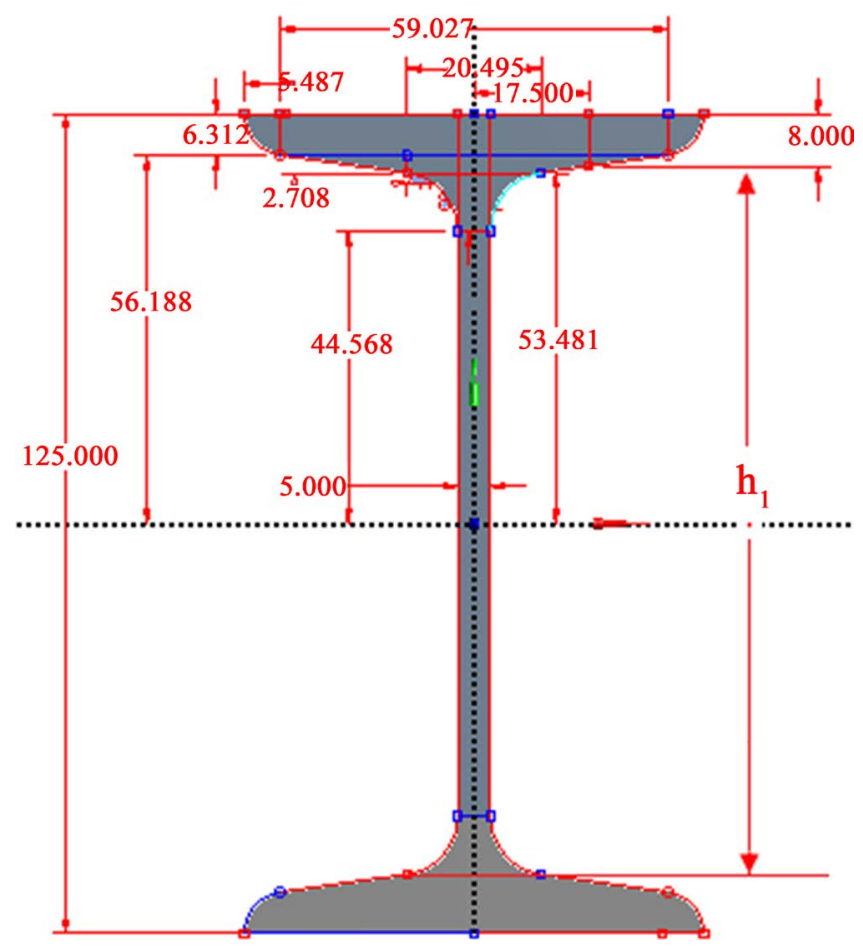

Figure 8. Sectional dimensions (all dimensions are in $\mathrm{mm}$ ) for calculation of area, moment of inertia and shear constant.

Studying these variations within a section helps in deciding a particular value of it for maximum performance hence optimum design.

\subsection{Effect of Changing Depth (D) of the Cross-Section}

Following results (Figures 9-11) were obtained with a section of flange width $140 \mathrm{~mm}$. All other parameters were kept constant and depth is varied from $100 \mathrm{~mm}$ to $650 \mathrm{~mm}$.

With the results of Figure 9, mass of the section increases linearly as the depth of the section increases.

Important observations can be seen with the graph of Figure 10. It can be observed that as the depth of the section increases at some limit, performance of the beam decreases rapidly. Further increase in depth results in improving negligible performance of the beam.

In the performance graph, it can be observed that the limit of this depth is around $300 \mathrm{~mm}$ which is approximately double the width of the section.

Safely factor increases linearly as the depth of the section increases (Figure 11). Studying these variations suitably helps in deciding the optimum value of the depth of the section. Although these variations may be different if studied with different dimensions but more or less behavior remains the same.

\subsection{Effect of Changing Web Thickness ( $\mathrm{t}$ ) of the Cross-Section}

If web thickness of the section is increased mass of the section increases linearly (Figure 12). In the graphs of the Figure 13 and Figure 14, it can be observed that till certain value, performance of the beam increases rapidly as total deformation reduces and safety factor also increases with high gradient of the graph. In this case after around $8 \mathrm{~mm}$ of web thickness, increasing the web thickness gives negligible increment in the performance of the section.

So, suitably selecting web thickness optimizes the section for maximum performance.

\subsection{Effect of Changing Fillet Radius $\left(R_{1}\right)$ the Cross-Section}

Increasing radius of fillet increases the mass of the section in a curved path with the increasing gradients (Figure 15) and with the same proportion it improves the performance of the section (Figure 16 and Figure 17). 


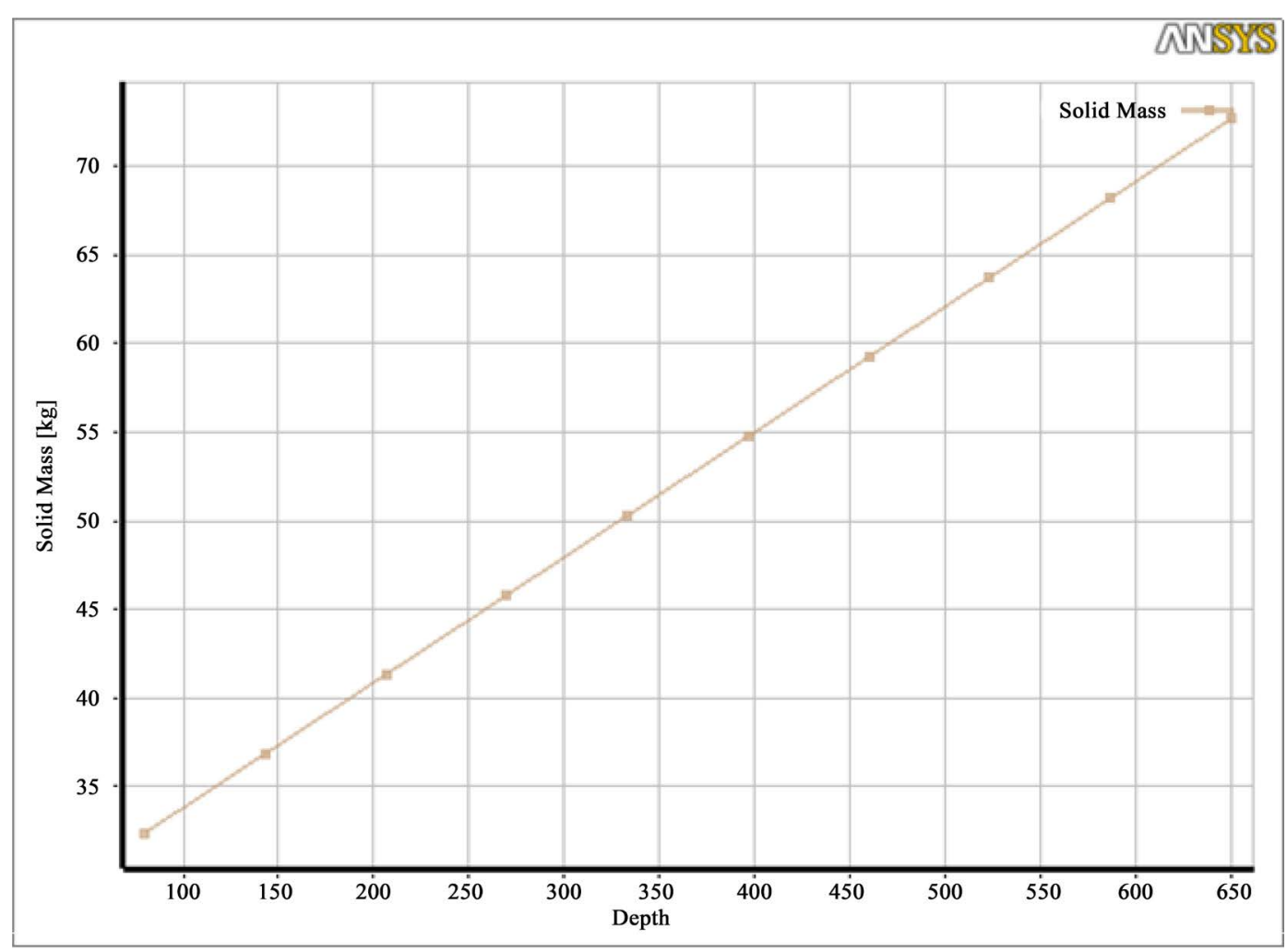

Figure 9. Variation of mass of the beam (per meter length) as depth of the section varies.

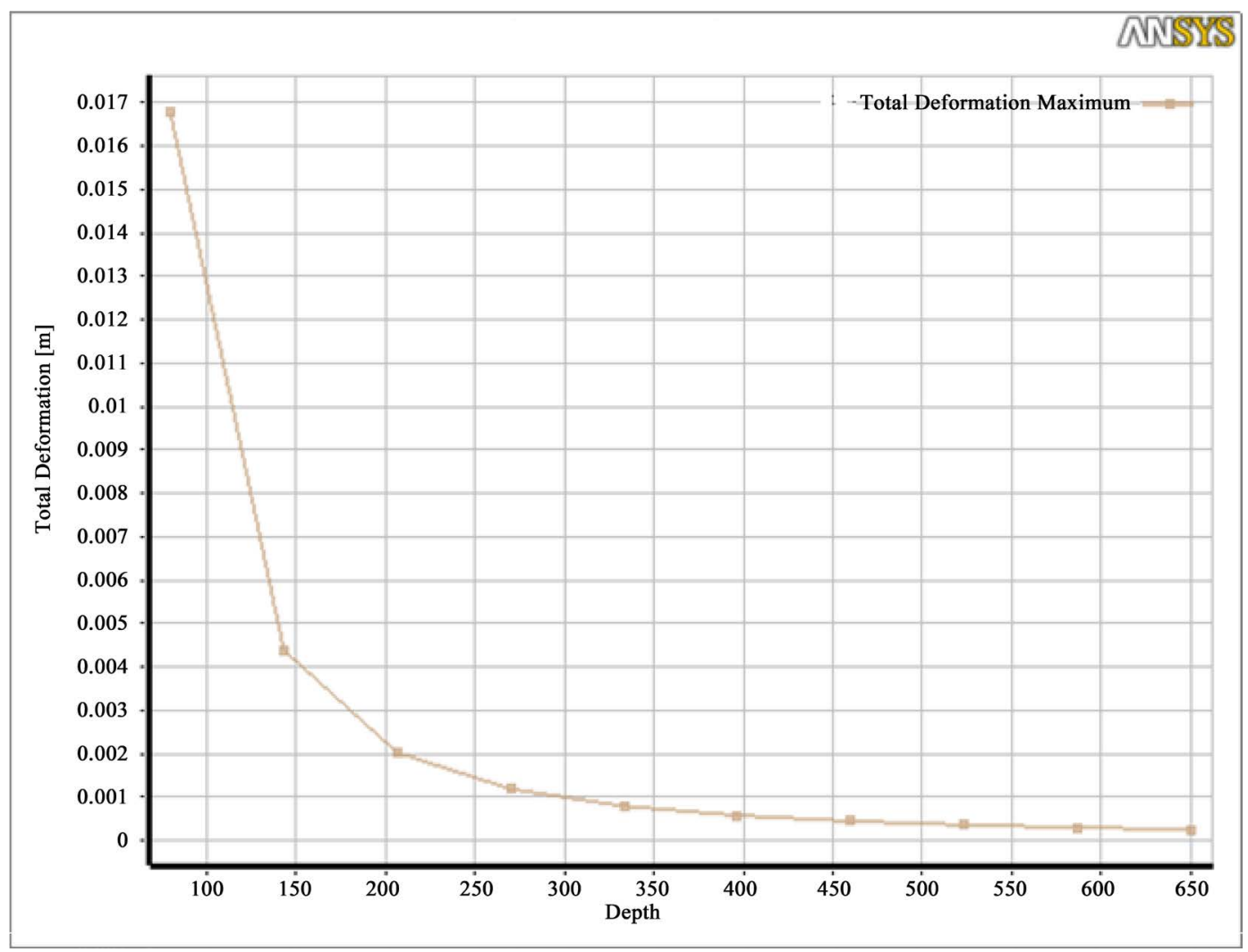

Figure 10. Variation in max. total deformation of the beam as depth (D) of the section varies. 


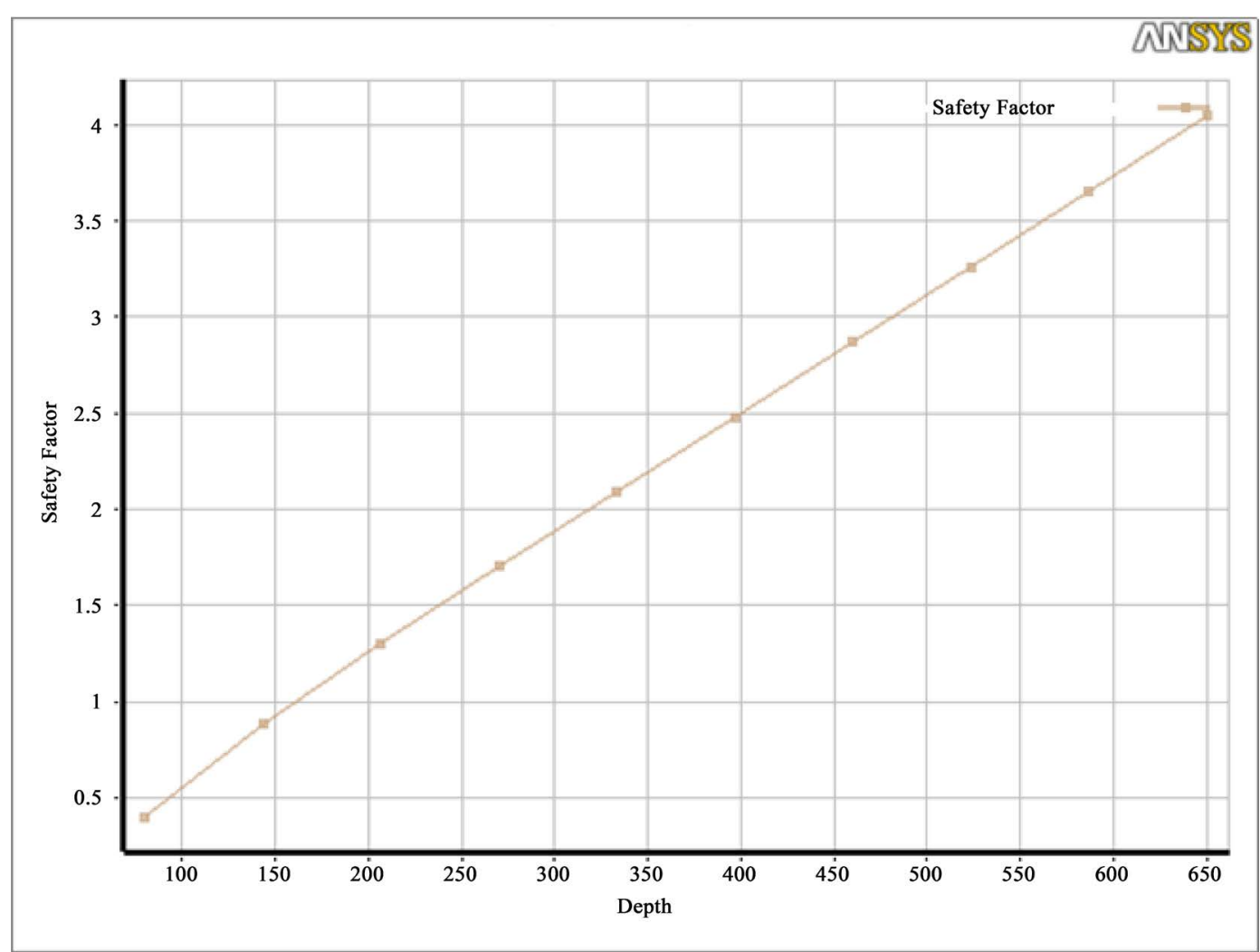

Figure 11. Variation in safety factor as depth (D) of the section varies.

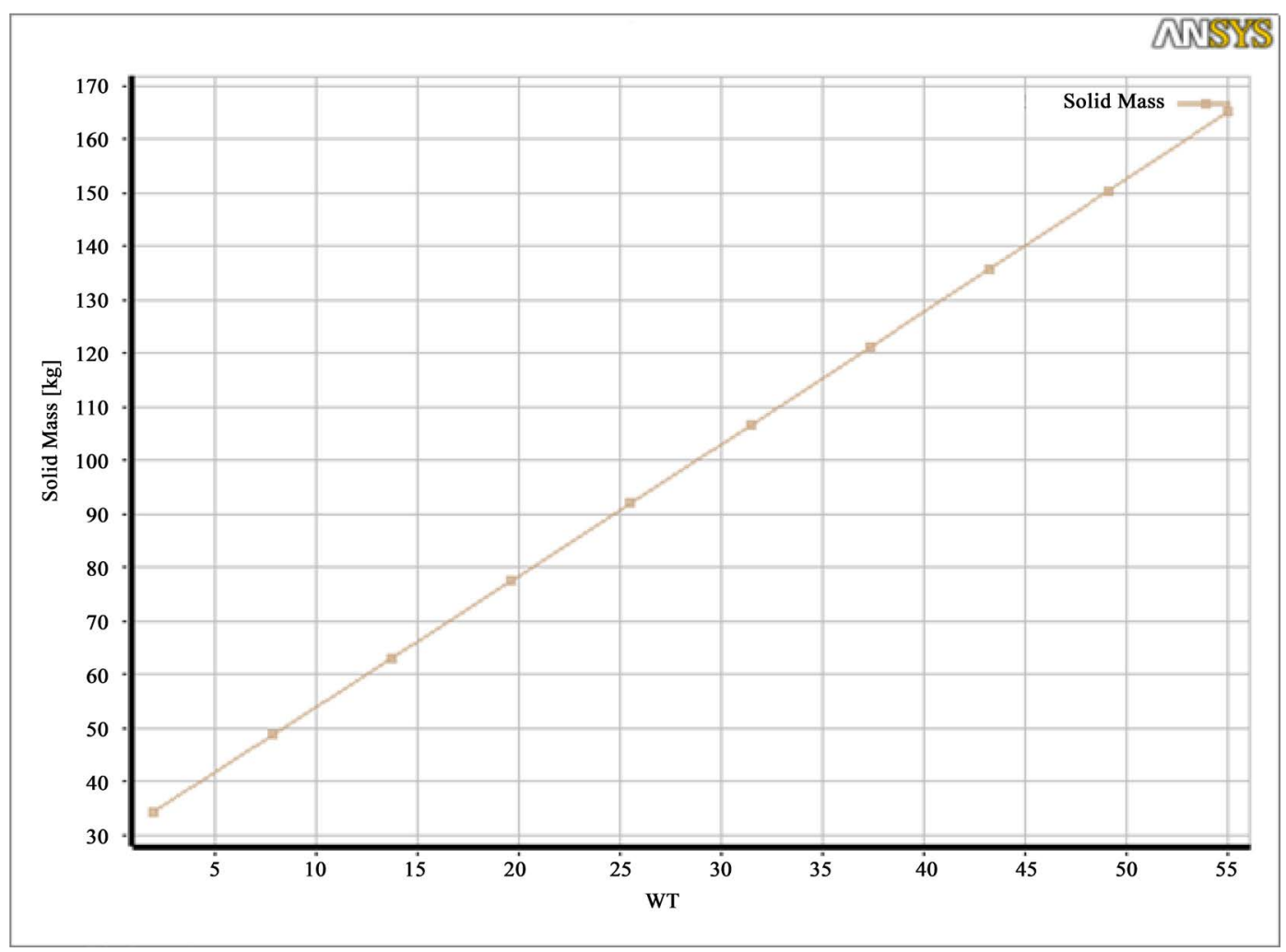

Figure 12. Variation of mass of the beam (per meter length) as web thickness (t) of the section varies. 


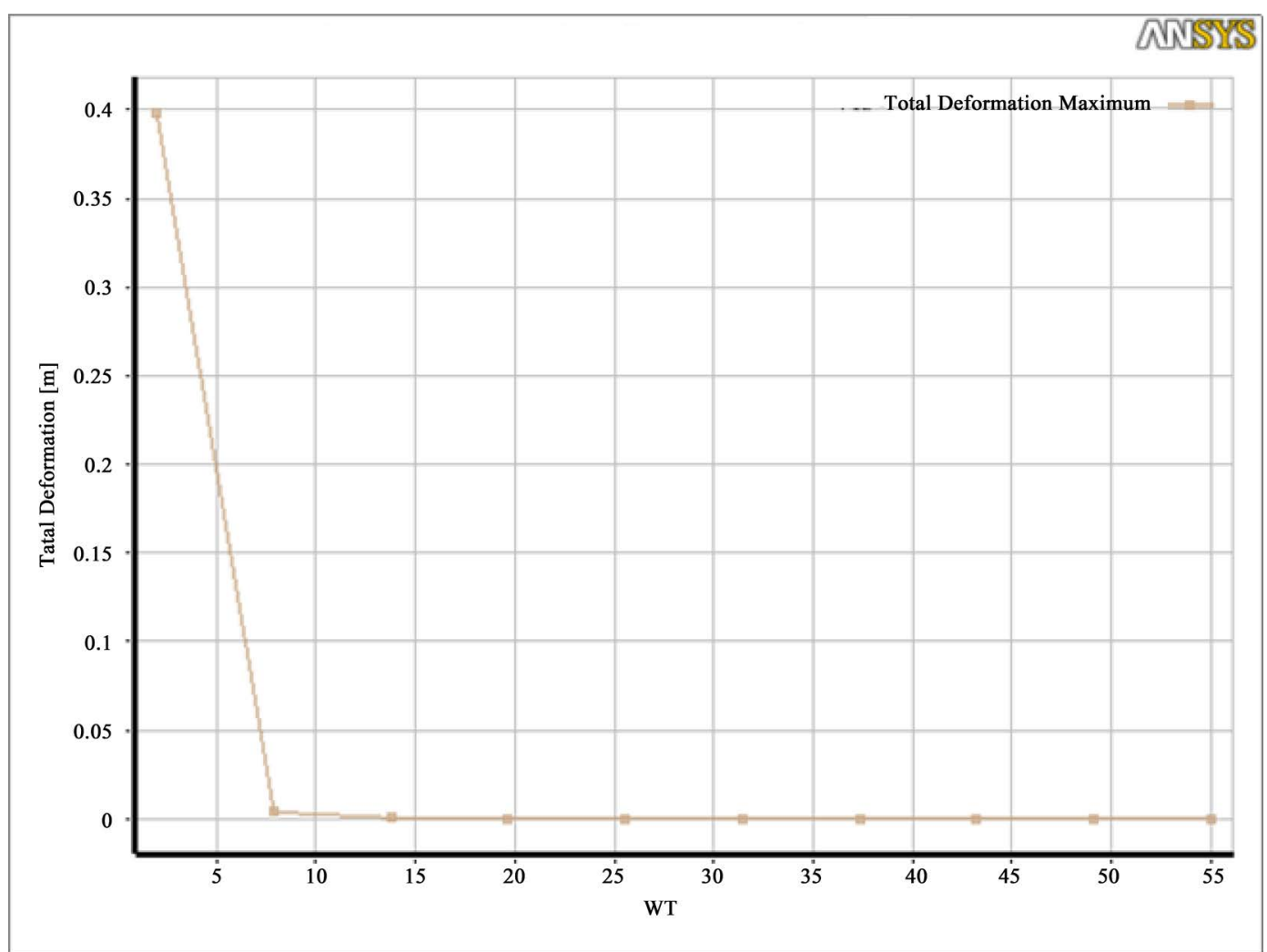

Figure 13. Variation in max. total deformation of the beam as web thickness $(\mathrm{t})$ of the section varies.

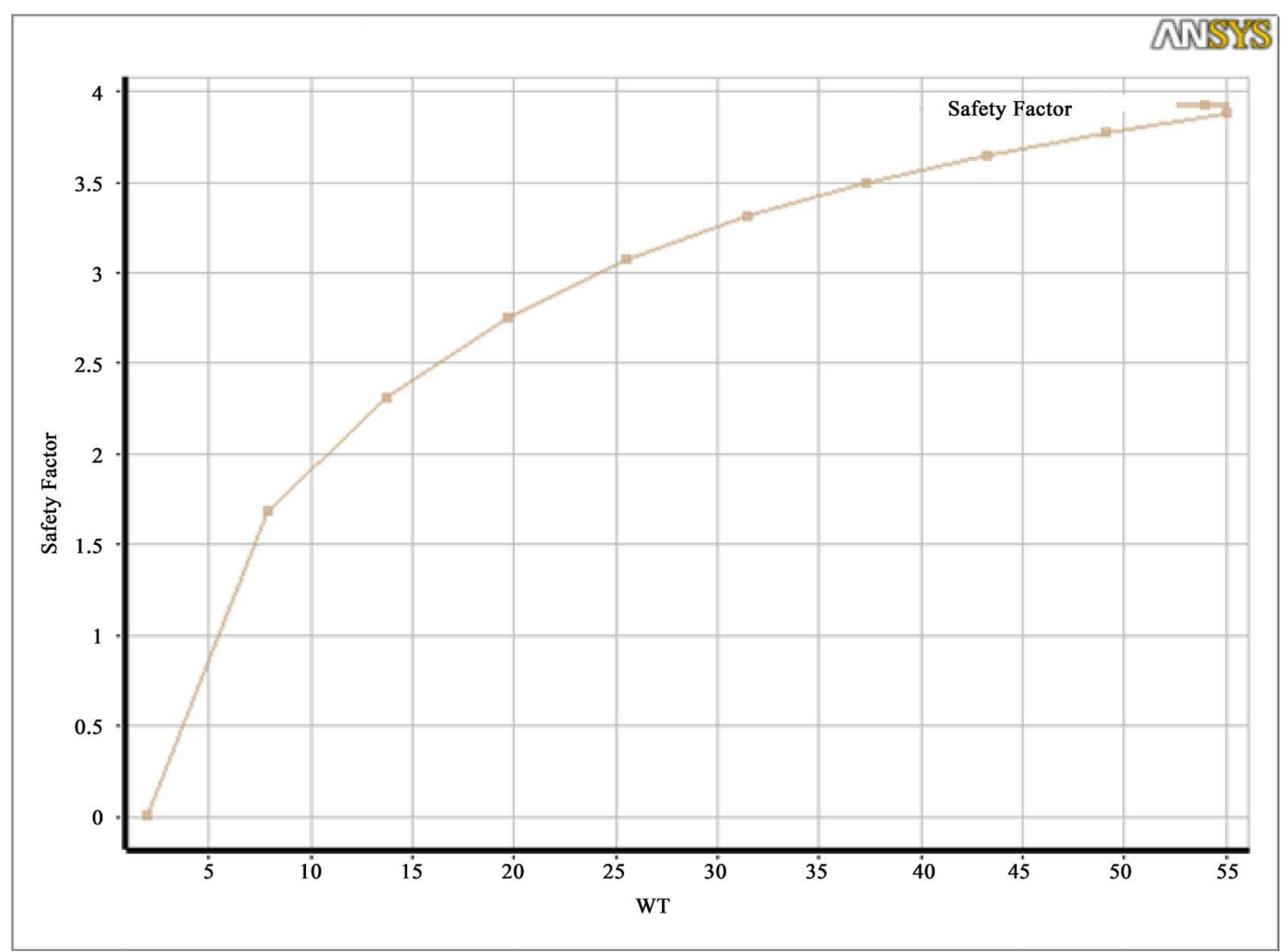

Figure 14. Variation in safety factor as web thickness (t) of the section varies. 


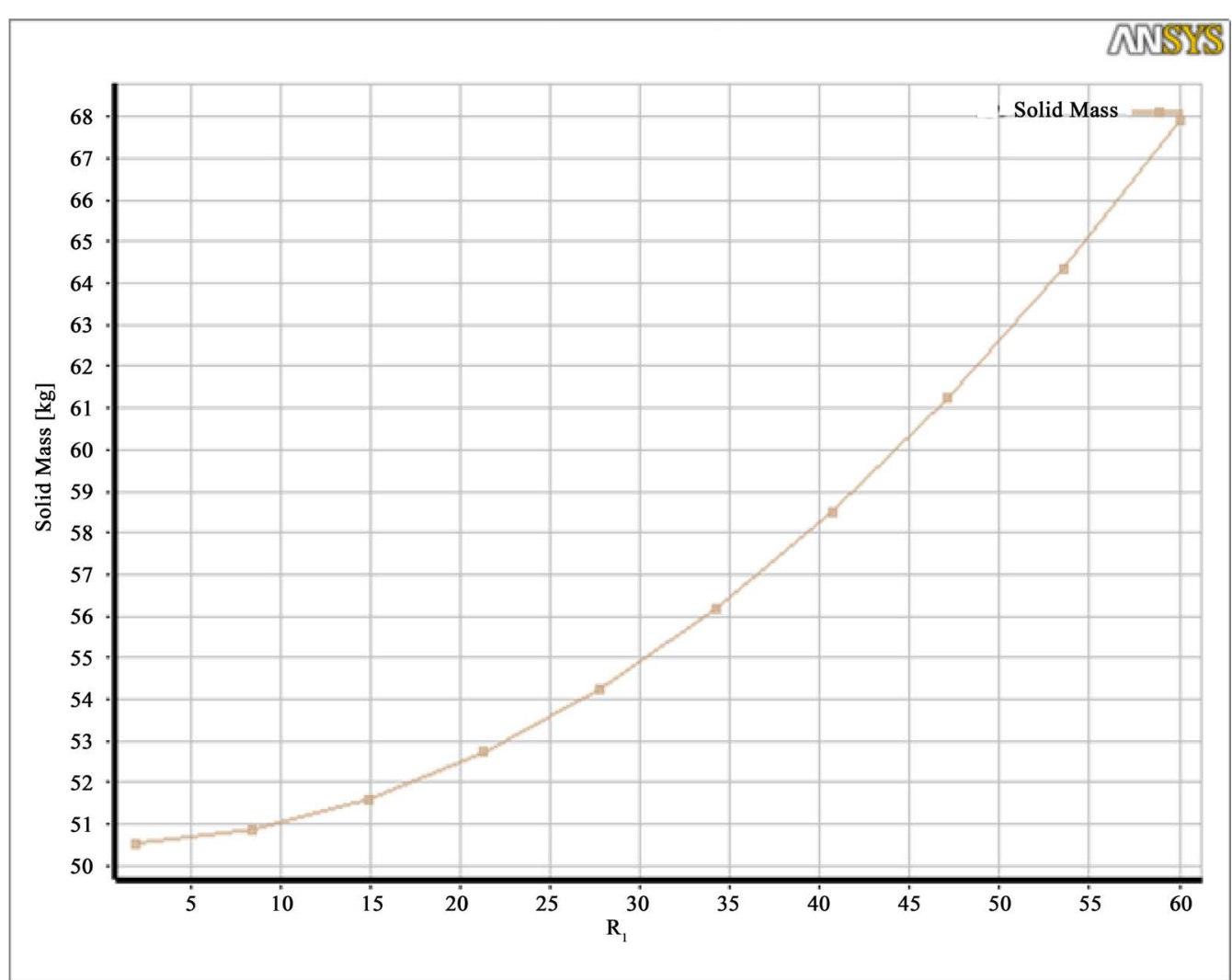

Figure 15. Variation of mass of the beam (per meter length) as fillet radius $\left(\mathrm{R}_{1}\right)$ of the section varies.

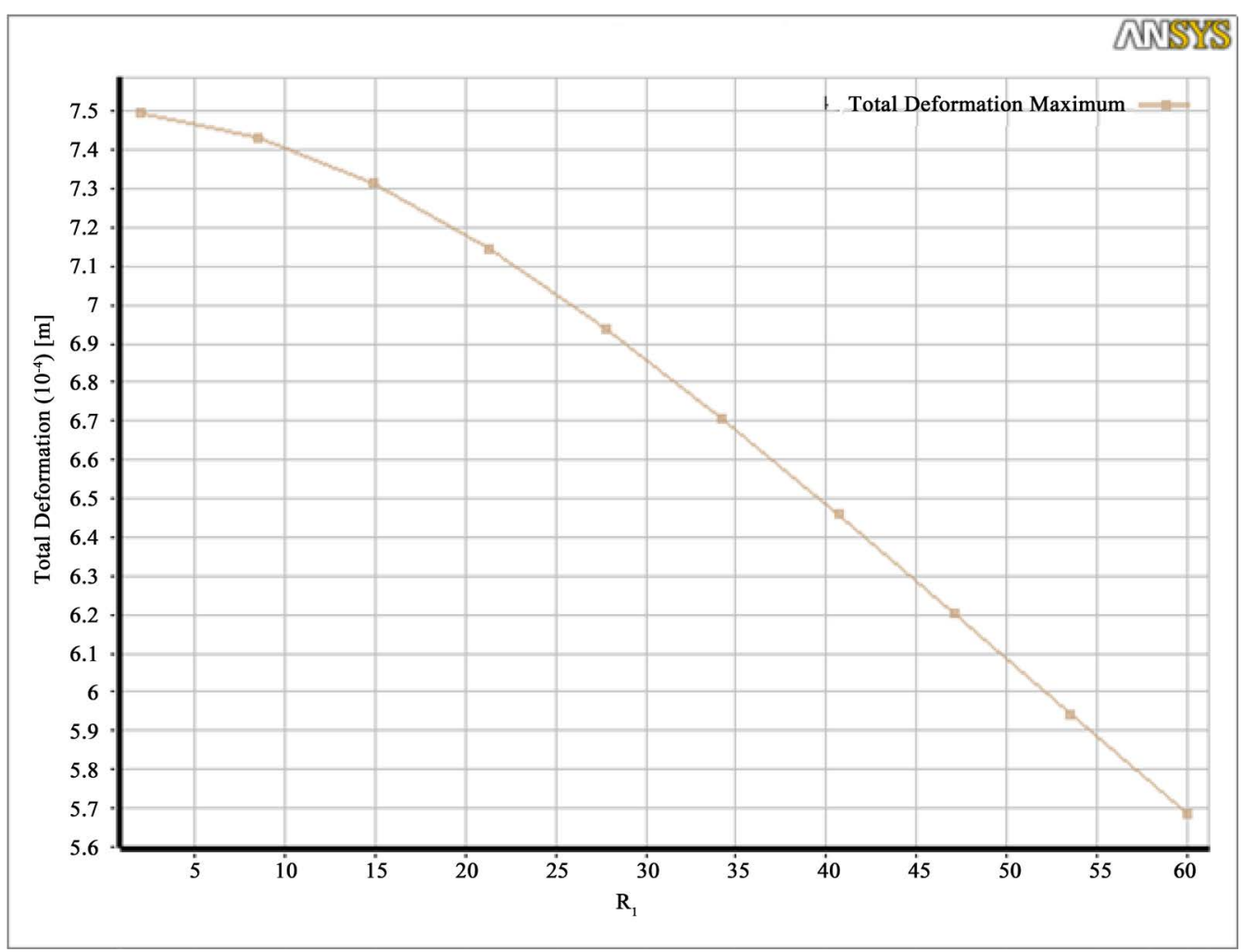

Figure 16. Variation in max. total deformation of the beam as fillet radius $\left(\mathrm{R}_{1}\right)$ of the section varies. 


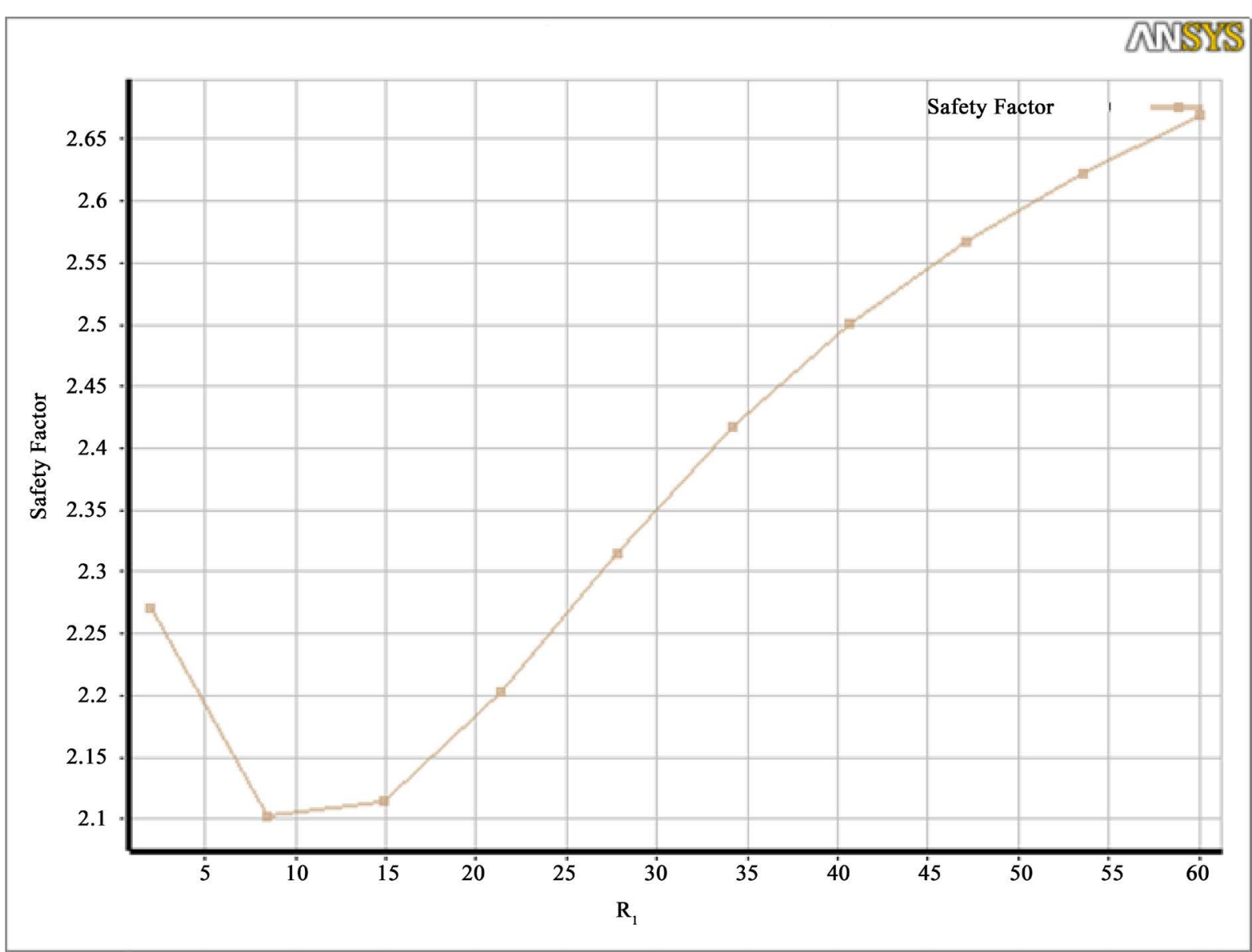

Figure 17. Variation in safety factor as fillet radius $\left(\mathrm{R}_{1}\right)$ of the section varies.

Using very small radius of fillet is not suitable for designing the section (Figure 17).

\subsection{Effect of Changing Flange Width (B) of the Cross-Section}

In the following Figures 18-20, on the horizontal axis, numerical values are for B/4 (Figure 1). Geometry of the beam was created such that putting the $\mathrm{B} / 4$ value makes this dimension. This was because of the constraint that flange thickness has to be decided at the $\mathrm{B} / 4$ distance from the centroidal axis.

Performance of the section with both the parameters, flange width and flange thickness, is almost same and can also be compared with the graphs of Figures 21-23.

\subsection{Effect of Changing Flange Thickness ( $\mathrm{T}$ ) of the Cross-Section}

In the graphs of Figures 19-23, it can be observed that with increasing the width and depth of the flange improves the performance of the section with increasing gradient whereby increasing the mass linearly (Figure 18 and Figure 21).

So increasing the flange width or thickness of the section is the effective way of increasing the performance of the section. It increases the mass in a linear path whereby increases the performance of the section with higher gradients.

\subsection{Effect of Changing Flange Slope $(\alpha)$ of the Cross-Section}

Astonishing results are found for any section when flange slope changes within the geometric limits. In Figure 24 , mass of the section is decreasing rapidly as the flange slope increases. Instead performance of the section increases rapidly (Figure 25 and Figure 26). 


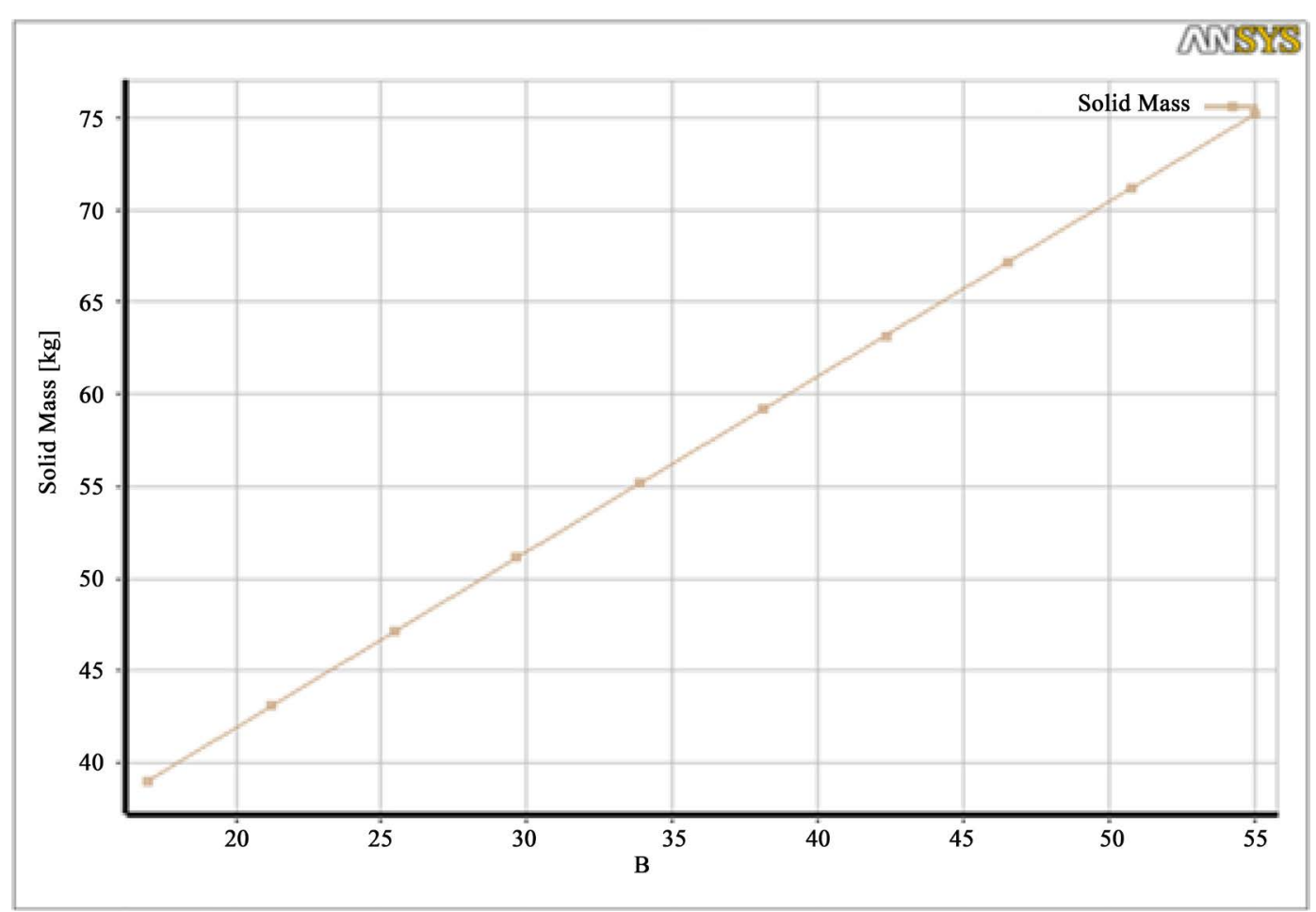

Figure 18. Variation of mass of the beam (per meter length) as flange width (B) of the section varies.

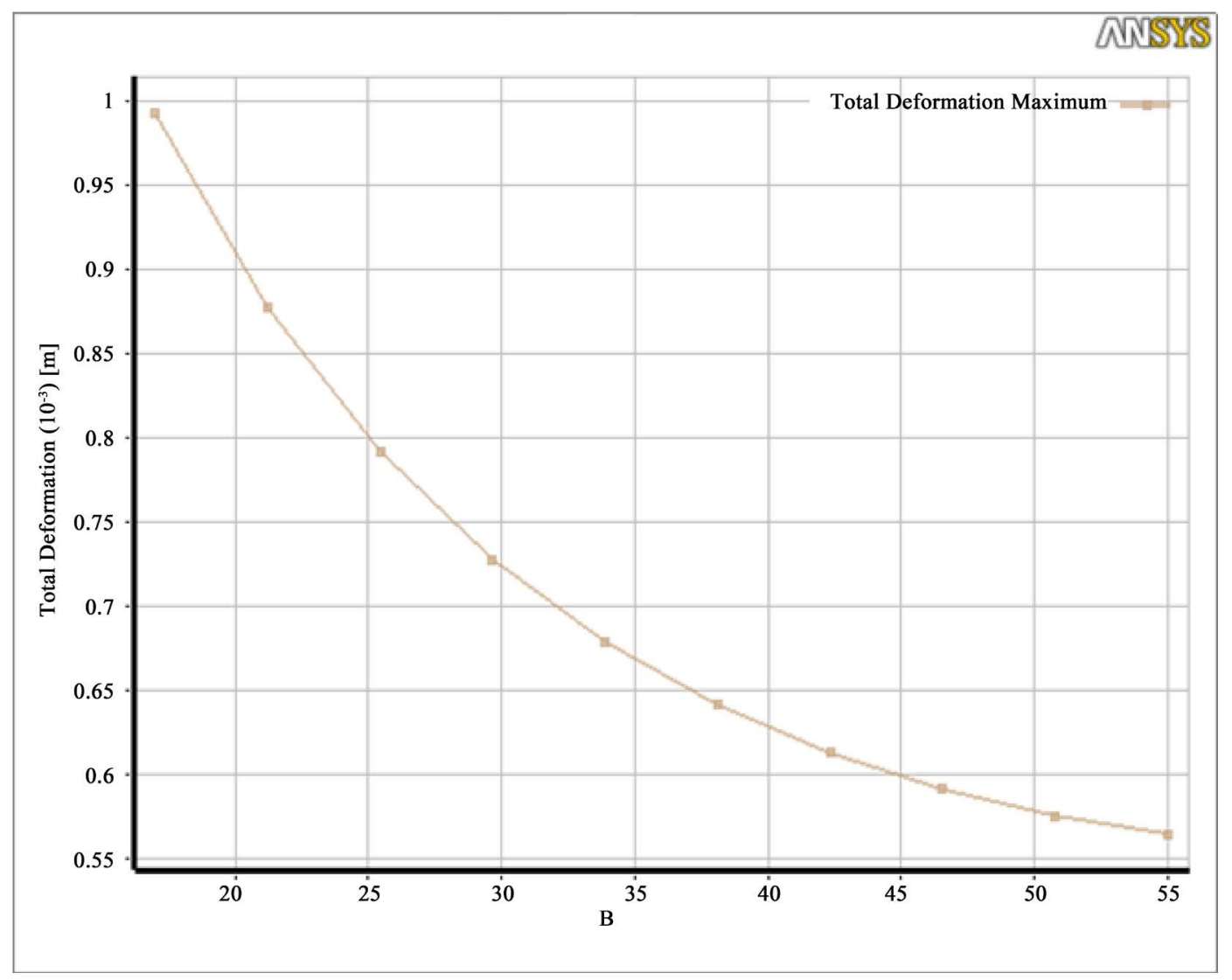

Figure 19. Variation in max. total deformation of the beam as flange width (B) of the section varies. 


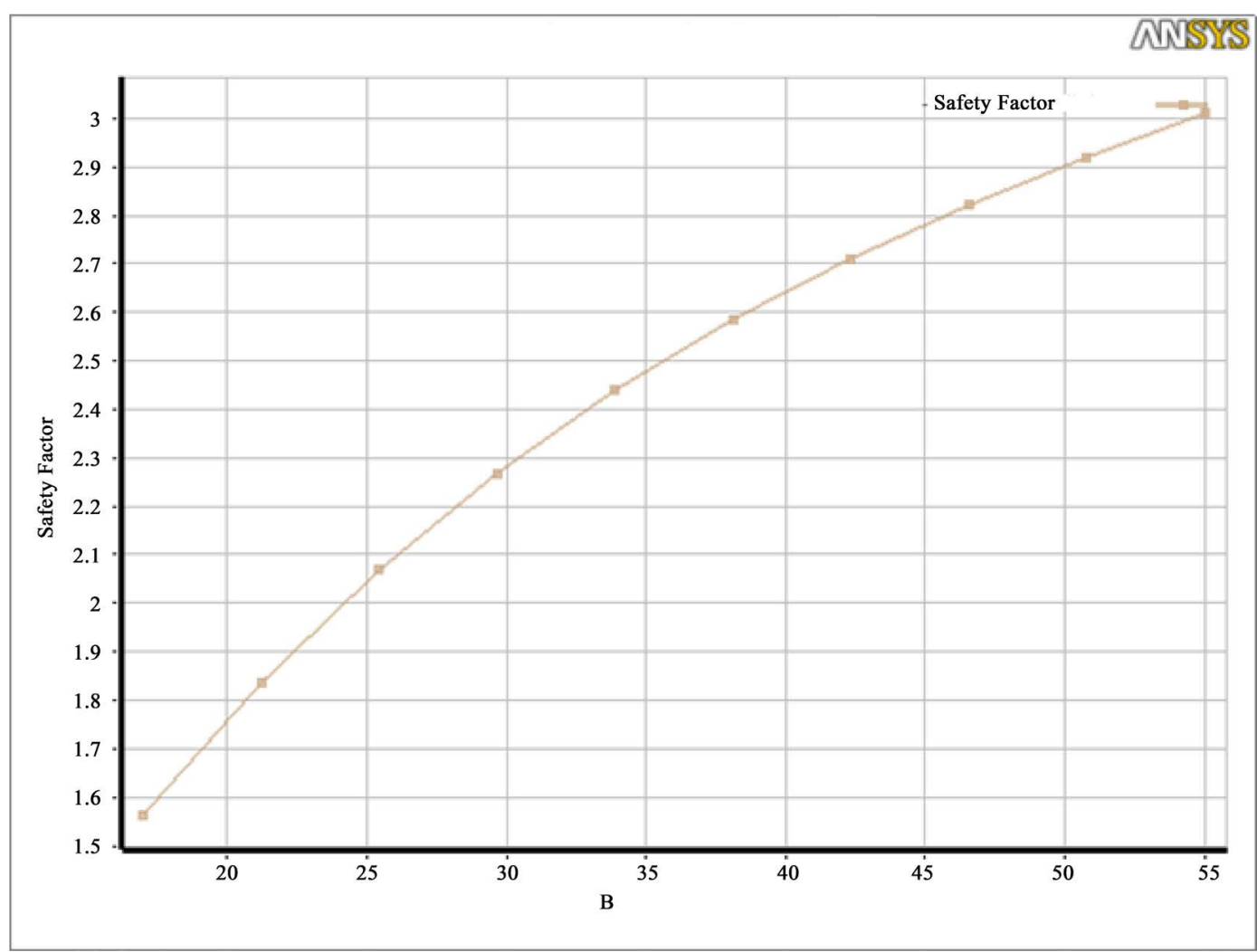

Figure 20. Variation in safety factor as flange width (B) of the section varies.

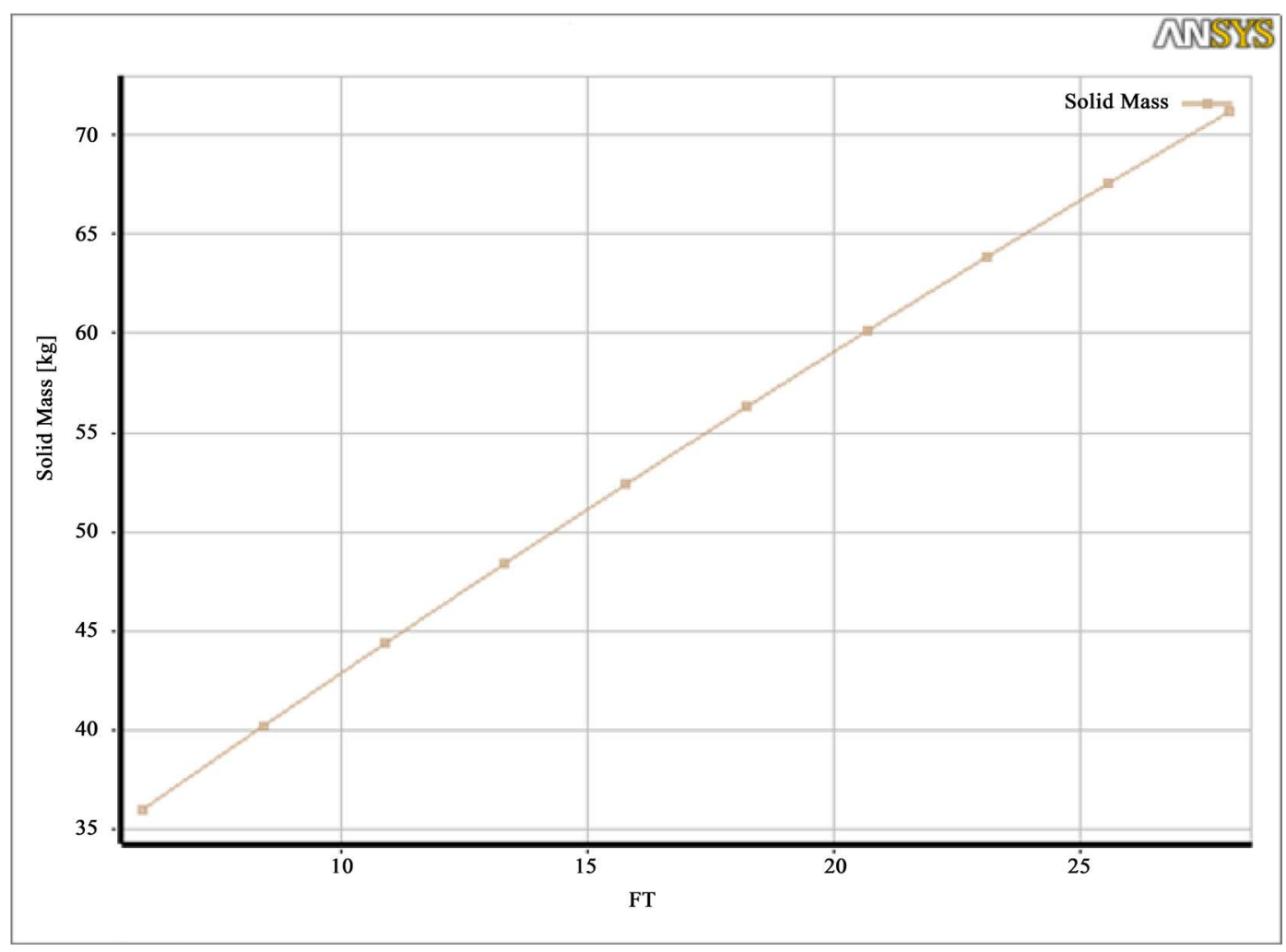

Figure 21. Variation of mass of the beam (per meter) as flange thickness (T) of the section varies. 


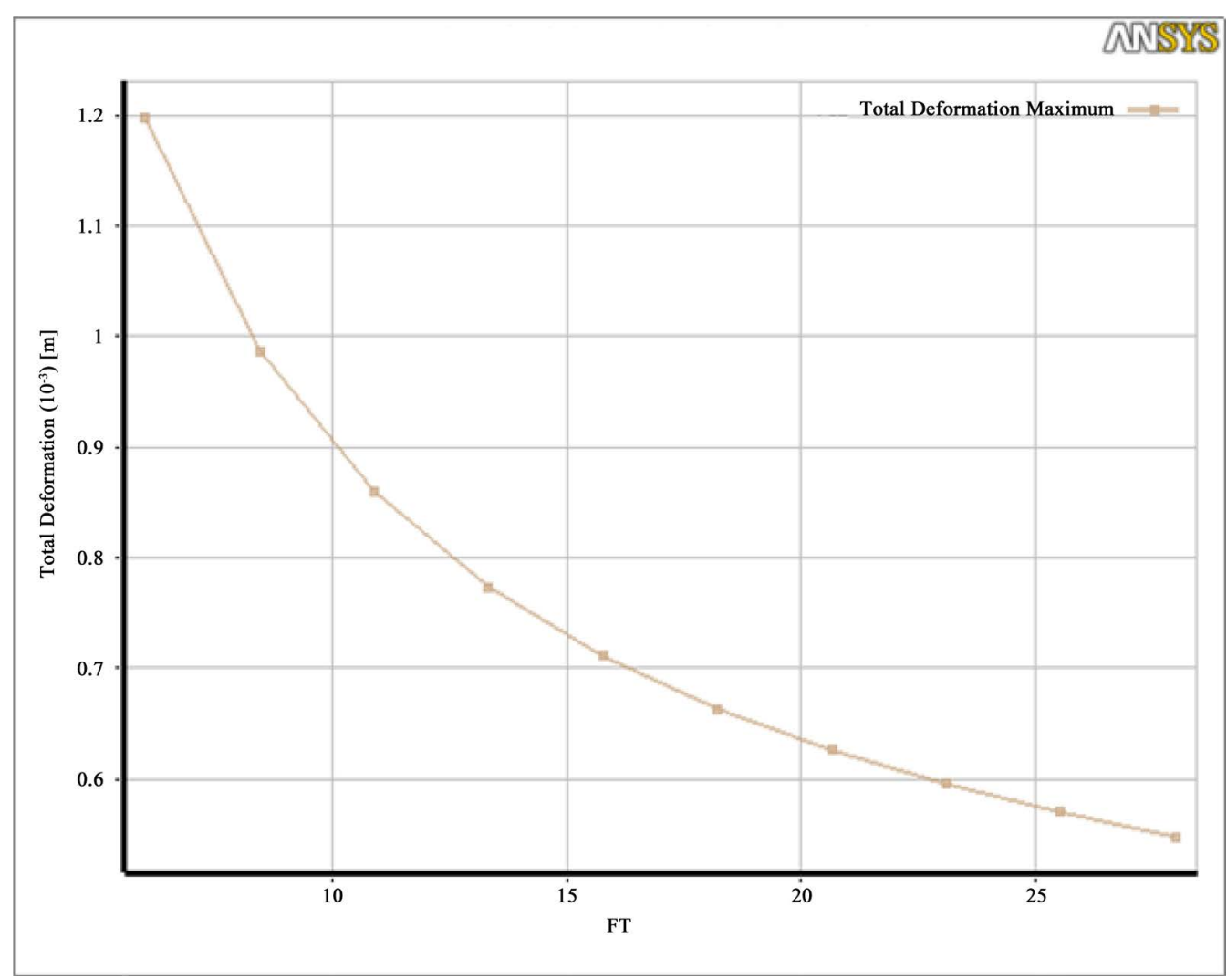

Figure 22. Variation in max. total deformation of the beam as flange thickness $(\mathrm{T})$ of the section varies.

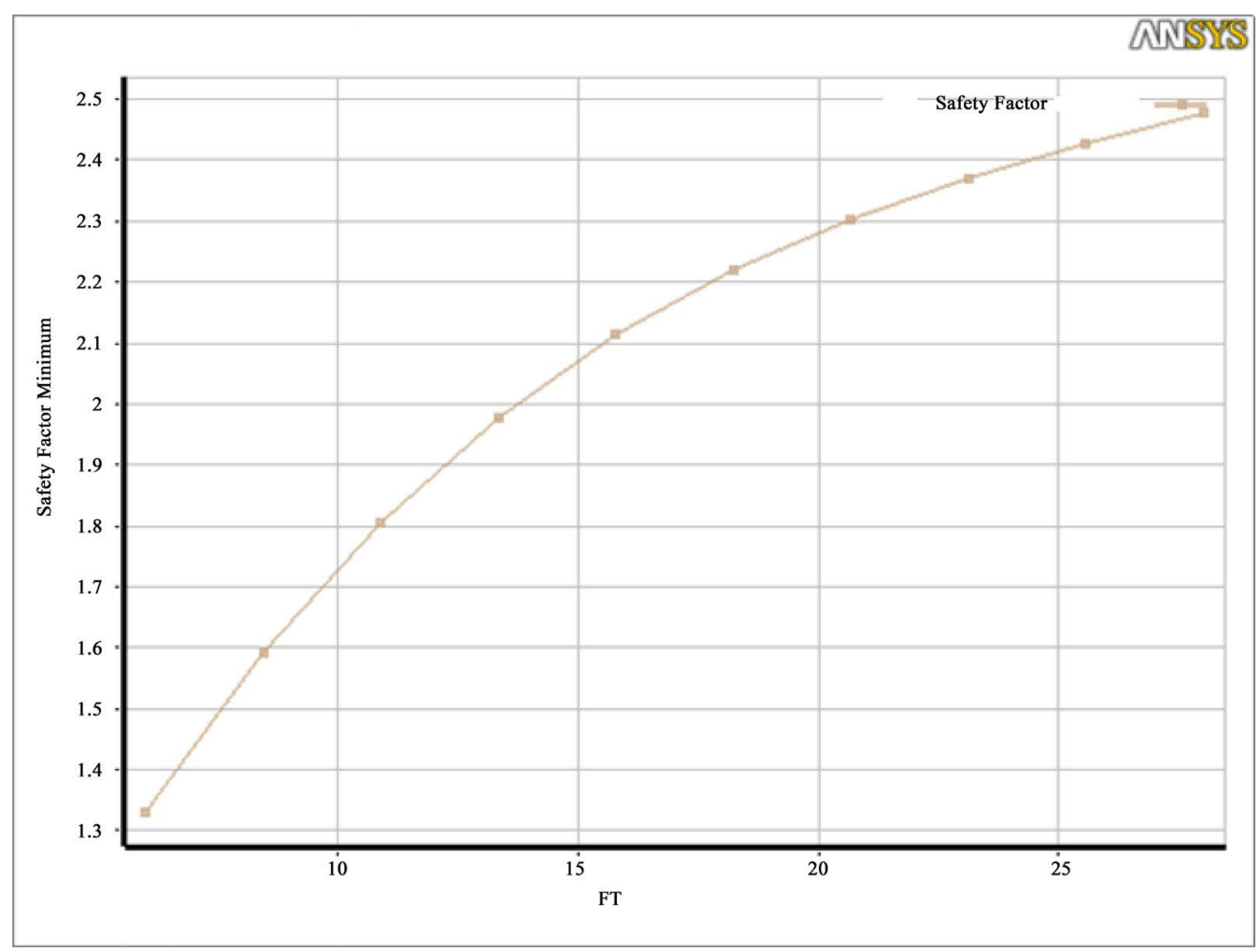

Figure 23. Variation in safety factor as flange thickness $(\mathrm{T})$ of the section varies. 


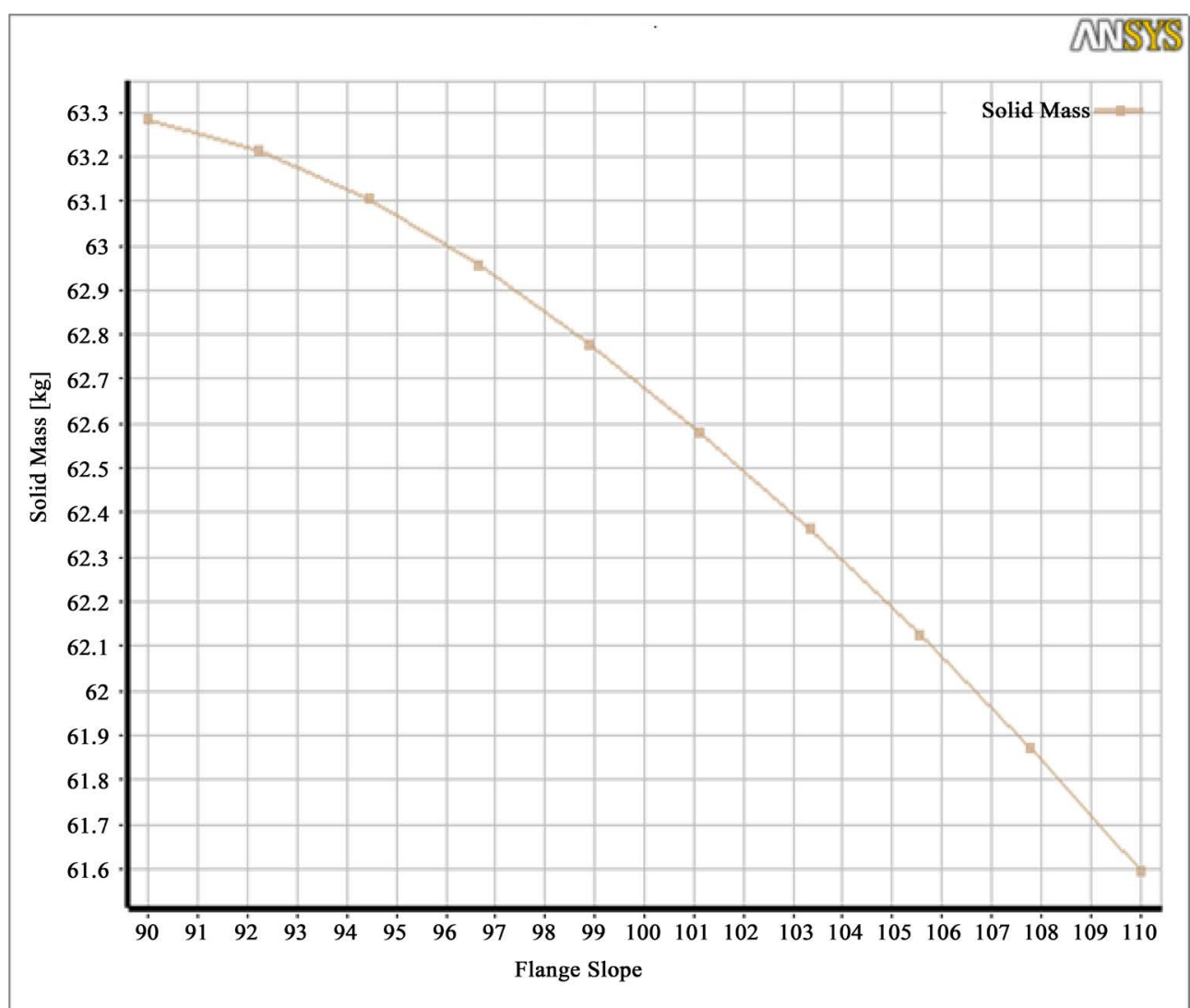

Figure 24. Variation of mass of the beam (per meter length) as flange slope $(\alpha)$ of the section varies.

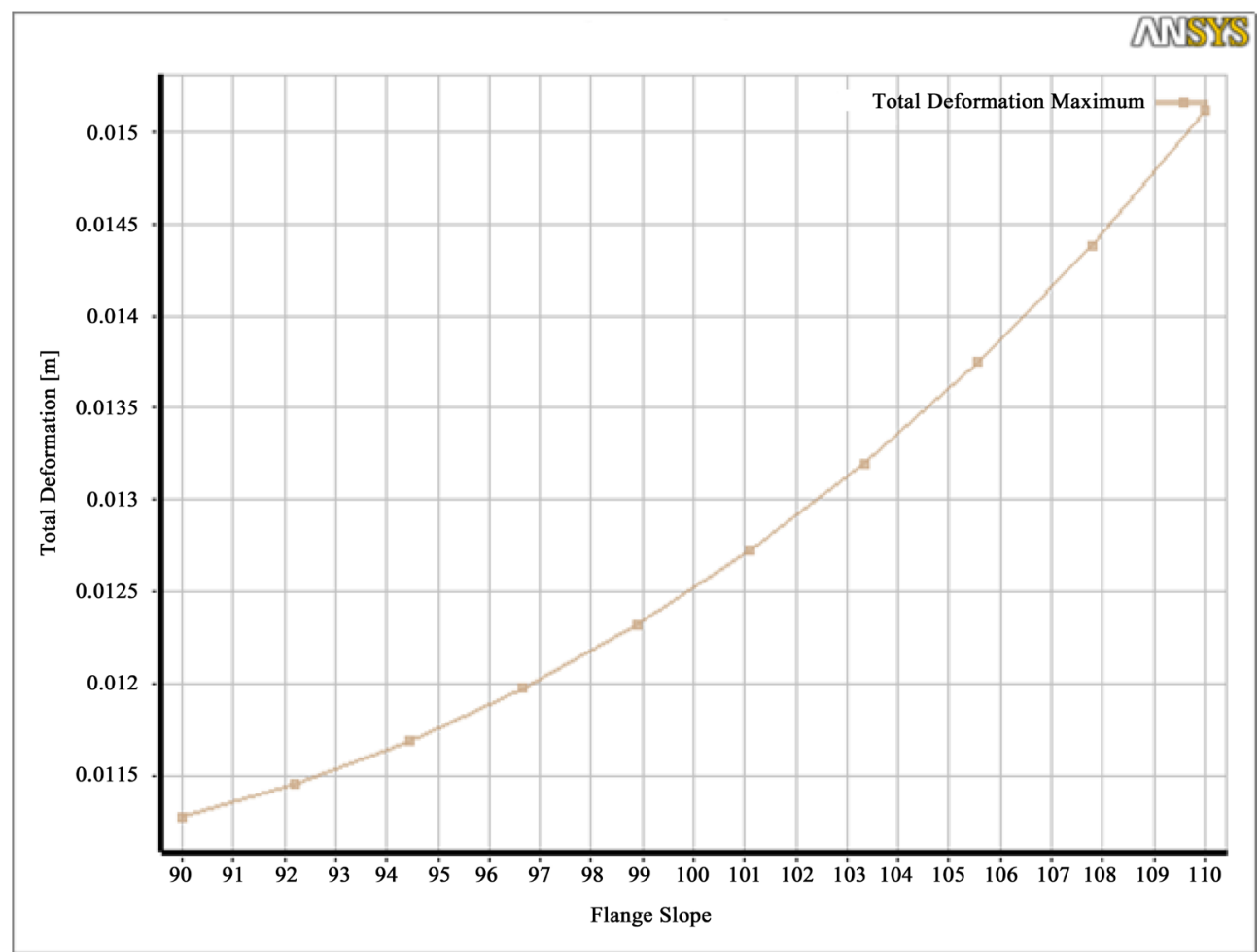

Figure 25. Variation in max. total deformation of the beam as flange slope $(\alpha)$ of the section varies. 
This is the only parameter which is found like increasing its value decreases the mass whereby improving the performance of the section with high gradients. It improves the performance of the section without increasing the mass proportionally.

With the results of safety factor of Figure 26, it can be stated that flange slope is good if it is adopted within $92^{\circ}$ to $97^{\circ}$. This is the peak range that is giving maximum value of safety factor and should be adopted for designing.

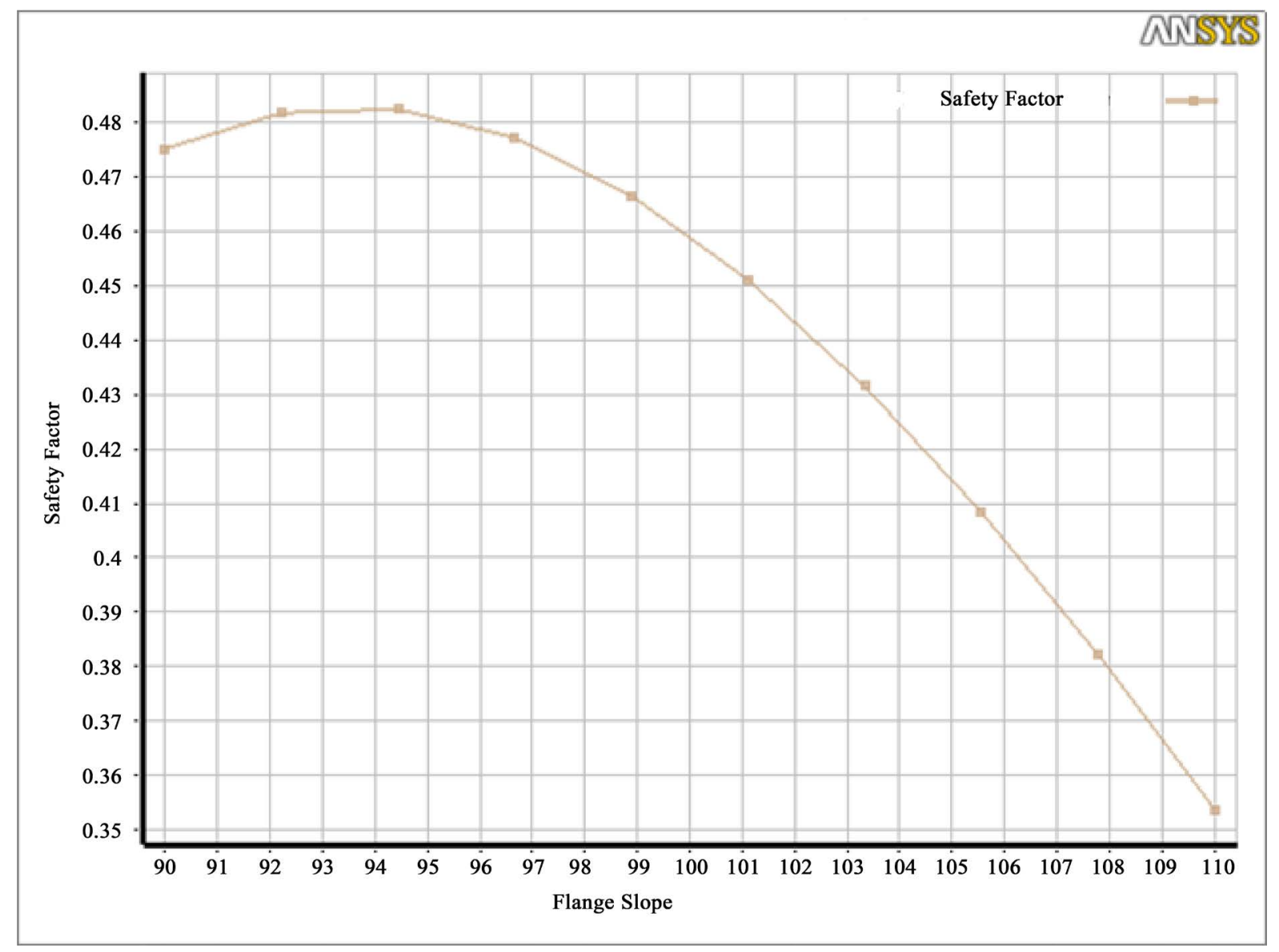

Figure 26. Variation in safety factor as flange slope $(\alpha)$ of the section varies.

\section{Results and Discussions}

For any arbitrary loading, following results are found out for IS sections as well as for optimally suggested sections. It can be observed in the this Table 2 that for the same mass, performance of the suggested optimal section, in terms of safety factor as well as for total maximum deformation is better than that of IS sections.

Table 2. Comparison of sections of IS 808 and obtained optimal sections after analysis.

\begin{tabular}{|c|c|c|c|c|c|c|c|c|c|c|c|}
\hline S.N. & Sections & $\begin{array}{c}\mathrm{D} \\
(\mathrm{mm})\end{array}$ & $\begin{array}{c}\text { B } \\
(\mathrm{mm})\end{array}$ & $\begin{array}{c}\mathrm{t} \\
(\mathrm{mm})\end{array}$ & $\begin{array}{c}\alpha \\
\text { (deg) }\end{array}$ & $\begin{array}{c}T \\
(\mathbf{m m})\end{array}$ & $\begin{array}{c}\mathbf{R}_{1} \\
(\mathbf{m m})\end{array}$ & $\begin{array}{c}\mathbf{R}_{2} \\
(\mathbf{m m})\end{array}$ & $\begin{array}{c}\text { Mass } \\
(\mathrm{kg} / \mathrm{m})\end{array}$ & S.F & $\begin{array}{c}\text { T.M.D. } \\
\text { (mm) }\end{array}$ \\
\hline \multirow{2}{*}{1.} & MB 125 & 125 & 70 & 5 & 98 & 8 & 9 & 4.5 & 13.086 & 3.0541 & 1.934 \\
\hline & Optimal Section & 125 & 60 & 6 & 98 & 8.5 & 9 & 6.4 & 13.045 & 3.7034 & 1.812 \\
\hline \multirow{2}{*}{2.} & MB 300 & 300 & 140 & 7.7 & 98 & 13.1 & 14 & 7 & 45.3 & 2.5854 & 2.1137 \\
\hline & Optimal Section & 300 & 140 & 7 & 97 & 13.75 & 15 & 10.7 & 45.296 & 2.6381 & 2.0023 \\
\hline \multirow{2}{*}{3.} & MB 400 & 400 & 140 & 8.9 & 98 & 16 & 14 & 7 & 60.396 & 2.1315 & 2.6412 \\
\hline & Optimal Section & 400 & 148 & 8.8 & 95 & 15 & 15 & 12.9 & 60.323 & 2.3168 & 2.3861 \\
\hline
\end{tabular}


For better validation of these results, following structural errors are found in discretization of the model geometry (Figure 27). Unit of this measurement is Joule.

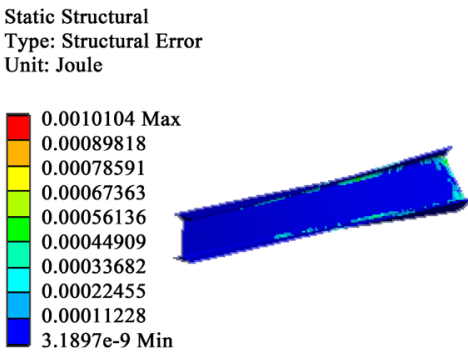

MB 125
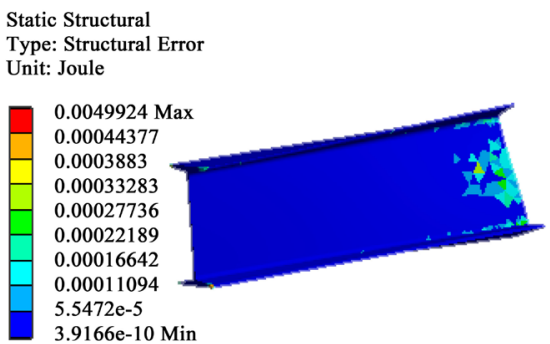

MB 300
Static Structural

Type: Structural Error

Unit: Joule

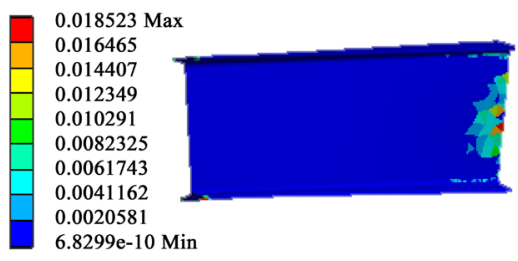

MB 400

Figure 27. Figure shows discretization error in different sections.

\section{Conclusions}

Figure 28 and Figure 29 show statistics of results which come out from this analysis. These statistics show the potential of the inferiority of these three sections together and the need for correcting them in their dimensions. From these figures, it can be concluded that:

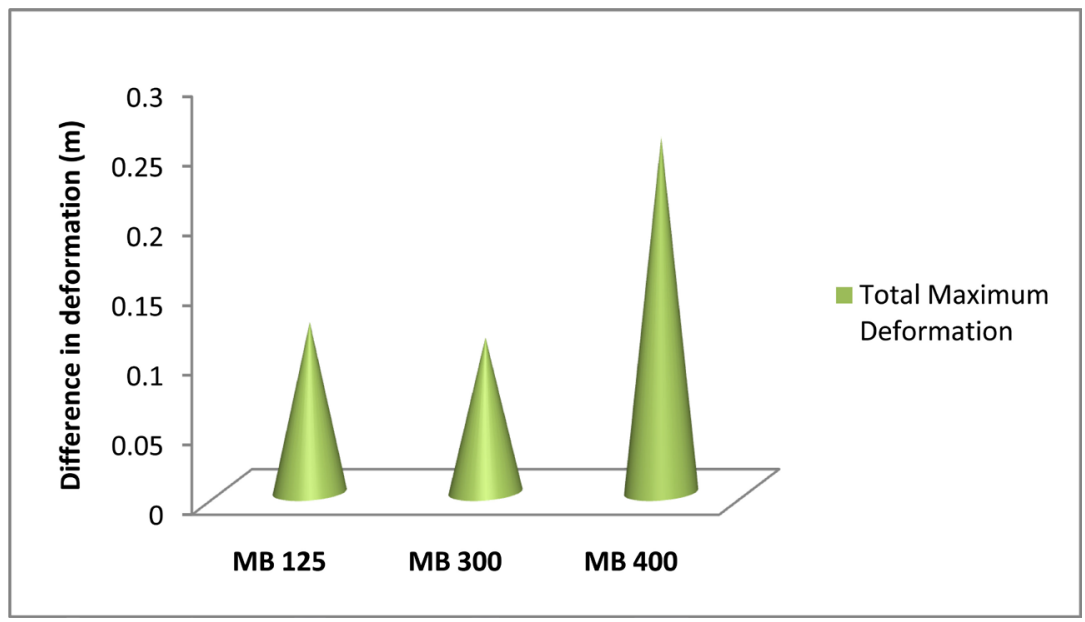

Figure 28. Figure shows difference in deformation in optimal section and IS sections.

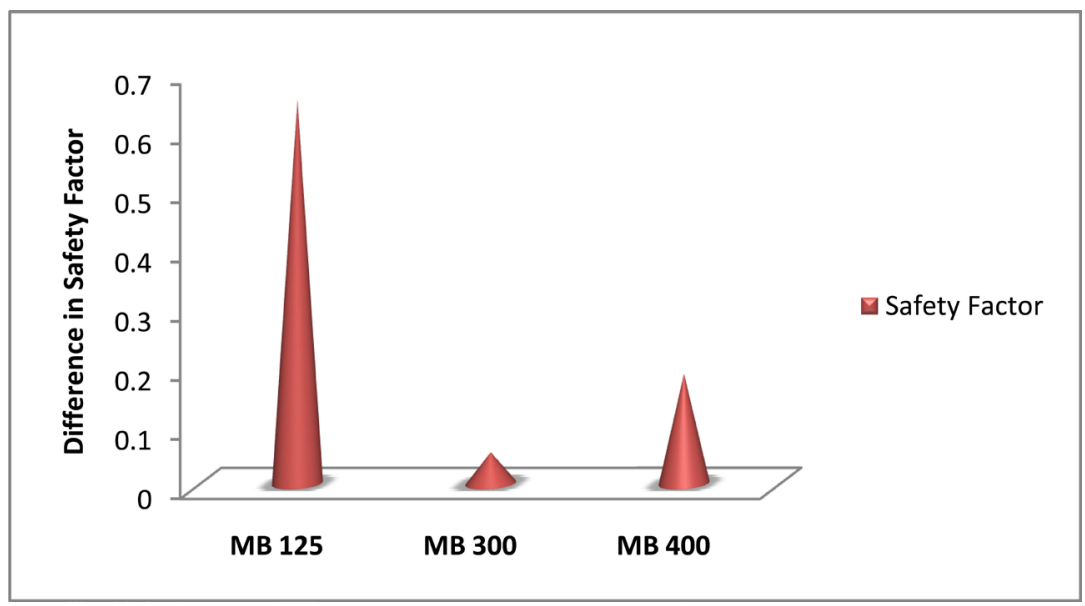

Figure 29. Figure shows difference in safety factor of optimal section and IS sections. 
- Section MB 125 should be changed for the parameters, preferably flange width (B) and flange thickness (T) so that the safety factor of the section can be increased.

- Section MB 400 should be amended for the sectional dimension, preferably for flange width (B), web thickness $(t)$ and flange slope $(\alpha)$ so that the total deformation of the section can be reduced.

- Section MB 300 should be amended such that deformation as well as the safety factor can be improved and the suggestions are web thickness $(\mathrm{t})$, flange thickness $(\mathrm{T})$ and flange slope $(\alpha)$.

Except these three sections of IS 808, Table 1, no other section is found to be performing inferiorly. With this study, it is certain that there exist better sectional dimensions for these three sections. Since IS sections are used countrywide by the designers and are manufacturers. So it will be the good practice if these sections are changed for their better alternatives.

Further, this study can be performed for the other sections of IS 808 for the better performance of the sections.

\section{References}

[1] BIS (1987) IS 808: 1989 Indian Standard Dimensions for Hot Rolled Steel Beam, Column, Channel and Angle Sections. Bureau of Indian Standard, New Delhi.

[2] Huang, X. and Xie, Y.M. (2010) Evolutionary Topology Optimization of Continuum Structures, Methods and Applications. A John Wiley and Sons, Ltd. Hoboken.

[3] Ghabraie, K., Xie, Y.M. and Huang, X. (2007) Shape Optimization of Underground Excavation Using ESO Method. Innovations in Structural Engineering and Construction, Melbourne, 26-28 September 2007. https://researchbank.rmit.edu.au/view/rmit:2848

[4] Beghini, L.L., Beghini, A., Katz, N., Baker, W.F. and Paulino, G.H. (2014) Connecting Architecture and Engineering through Structural Topology Optimization. Engineering Structures, 59, 716-726. http://dx.doi.org/10.1016/j.engstruct.2013.10.032

[5] Gere \& Timoshenko (2004) Mechanics of Material. CBS Publishers and Distributers Pvt. Ltd., Chennai

[6] Timoshenko, S. (2002) Strength of Materials, Vol. 1, Elementary Theory and Problems. 3rd Edition, CBS, New Delhi.

[7] Ansys Help Manual—C 2010 SAS IP, Inc.

[8] Benzley, S.E., Perry, E., Merkley, K. and Clark, B. (1995) A Comparison of All-Hexahedra and All Tetrahedral Finite Element Meshes for Elastic \& Elastoplatic Analysis. Proceedings 4th International Meshing Round Table Sandia National Labs, Albuquerque, Livermore, October 1995, 179-181.

[9] Canann, S.A., Tristano, J.R. and Staten, M.L. (1998) An Approach to Combined Laplacian and Optimization-Based Smoothing for Triangular, Quadrilateral, and Quad-Dominant Meshes. ANSYS, Inc., Canonsburg, 15317.

[10] Ergatoudis, I., Irons, B.M. and Zienkiewicz, O.C. (1968) Curved, Isoparametric, Quadrilateral Elements for Finite Element Analysis. International Journal of Solids and Structures, 4, 31-42.

[11] Ramsay, A.C.A. and Maunder, E.A.W. (1995) Effective Error Estimation from Continuous, Boundary Admissible Estimated Stress Field. Instituto Superior Técnico, Universidade Técnica de Lisboa, Lisboa.

[12] Cook, R., Malkus, D., Plesha, M. and Witt, R. (2010) Concept and Applications of Finite Element Analysis. John Wiley \& Sons (Asia) Pvt. Ltd., Hoboken. 